\title{
A novel tree seed algorithm for optimal reactive power planning and reconfiguration based STATCOM devices and PV sources
}

\author{
Mahdad Belkacem ${ }^{1}$
}

Received: 23 June 2020 / Accepted: 4 February 2021 / Published online: 16 February 2021

(c) The Author(s) 2021 OPEN

\begin{abstract}
Reactive power dispatch based on static synchronous compensator (STATCOM) and photovoltaic (PV) sources in coordination with reconfiguration strategy is vital task to ensure reliable operation of modern radial distribution (RD) systems. This paper introduces a novel tree seed algorithm (TSA) to improve the performance of modern RD power systems. A variant of TSA based on intelligent and flexible mechanism search is proposed to create an interactive equilibrium between exploration and exploitation during the search process to improve the global solution. Two objective functions, the total power loss and the margin reserve security are optimized under normal condition and critical load growth. To obtain reliable operation of the distribution system under critical situations, a reactive power dispatch based STATCOM devices is managed in coordination with the reconfiguration stage to find the best combination of sectionalizing switches and tie switches to be operated. The efficiency and particularity of the proposed distribution-planning strategy validated on two test systems, the radial 33 buses and the practical radial 250 buses $(30 \mathrm{kV}$ ) of Sonelgaz Company located in Biskra in the south of Algeria. This radial electric network designed principally to deliver energy to several small and important agricultural consumers. Results obtained based on various test cases and scenarios using the proposed new planning strategy confirm the efficiency of the proposed planning strategy in terms of reduction of the total power loss, improvement voltage magnitude and enhancement of margin reserve.
\end{abstract}

Keywords Reconfiguration · Tree seed algorithm · Radial distribution electric system · Reactive power planning · STATCOM - Power loss · PV source

\begin{tabular}{|c|c|c|c|}
\hline List of symbols & & Obj1 & Objective function related to total power \\
\hline Ploss $_{(k, k+1)}$ & Active power loss between bus $\mathrm{k}$ and & & loss \\
\hline & bus $k+1$ & Obj2 & Objective function related to margin \\
\hline Qloss $_{(k, k+1)}$ & Active power loss between bus $\mathrm{k}$ and & & reserve \\
\hline & bus $k+1$ & $M R$ & Margin reserve \\
\hline$R_{k, k+1}, X_{k, k+1}$ & $\begin{array}{l}\text { Resistance and reactance of line located } \\
\text { between bus } k \text { and bus } k+1\end{array}$ & $P_{t r, \text { slack }}, Q_{t r, \text { slack }}$ & $\begin{array}{l}\text { Active and reactive power of slack } \\
\text { transformer }\end{array}$ \\
\hline$P_{k, k+1}, Q_{k, k+1}$ & $\begin{array}{l}\text { Active and reactive power flow at line } \\
\text { located between bus } k \text { and bus } k+1\end{array}$ & $P_{D, i}, Q_{D, i}$ & $\begin{array}{l}\text { Active and reactive power load demand } \\
\text { in the bus } i\end{array}$ \\
\hline$V_{k}$ & Voltage magnitude at bus $\mathrm{k}$ & $V_{i}^{\min }, V_{i}^{\max }$ & Minimum and maximum voltage at bus $i$ \\
\hline$U_{\max }, U_{\min }$ & Maximum and minimum voltage & $n b r$ & Number of lines \\
\hline & magnitude. & $\mathrm{Npv}$ & Number of PV bus \\
\hline$P_{t, \text { loss }}$ & Total power loss. & $P_{p v, i}$ & $\begin{array}{l}\text { Active power delivered by PV source at } \\
\text { bus } i\end{array}$ \\
\hline
\end{tabular}

Mahdad Belkacem, bemahdad@yahoo.fr; belkacem.mahdad@univ-biskra.dz| ${ }^{1}$ University of Biskra, Biskra, Algeria. 


\begin{tabular}{|c|c|}
\hline$Q_{p v, i}$ & $\begin{array}{l}\text { Reactive power delivered by PV source } \\
\text { at bus } i\end{array}$ \\
\hline$P_{p v, i}^{\min }$ & $\begin{array}{l}\text { Minimum limit of active power delivered } \\
\text { by PV source located at bus } i\end{array}$ \\
\hline$P_{p v, i}^{\max }$ & $\begin{array}{l}\text { Maximum limit of active power deliv- } \\
\text { ered by PV source located at bus } i\end{array}$ \\
\hline$\mu$ & Penetration level of PV source \\
\hline$Q_{S t c, i}$ & $\begin{array}{l}\text { Reactive power delivered by STATCOM } \\
\text { device at bus } i \text {. }\end{array}$ \\
\hline$Q_{S t c, i}^{\min }$ & $\begin{array}{l}\text { Minimum reactive power delivered by } \\
\text { STATCOM device at bus } i \text {. }\end{array}$ \\
\hline$Q_{S t c, i}^{\max }$ & $\begin{array}{l}\text { Maximum reactive power delivered by } \\
\text { STATCOM device at bus } i \text {. }\end{array}$ \\
\hline$I_{b r i}$ & Current flow in line $i$ \\
\hline$I_{b r i}^{\max }$ & Maximum current flow in line $i$ \\
\hline$P_{i j}, Q_{i j}$ & Active and reactive power flow at lines \\
\hline$R_{i j}, X_{i j}$ & $\begin{array}{l}\text { Resistance and reactance of line con- } \\
\text { nected between bus } i \text { and bus } j\end{array}$ \\
\hline$U_{i}$ & Voltage magnitude at bus $i$ \\
\hline$d U_{i j}$ & $\begin{array}{l}\text { Voltage drop between bus } i \text { and bus } j \\
\text { before compensation }\end{array}$ \\
\hline$d U_{i j}^{c}$ & $\begin{array}{l}\text { Voltage drop between bus i and bus j } \\
\text { after compensation }\end{array}$ \\
\hline$Q_{i j}^{c}$ & $\begin{array}{l}\text { Reactive power flow between bus } i \text { and } \\
\text { bus } j \text { after compensation }\end{array}$ \\
\hline$S_{i j}^{o}$ & $\begin{array}{l}\text { Apparent power flow between bus } i \text { and } \\
\text { bus } j \text { before compensation }\end{array}$ \\
\hline$S_{i j}^{n}$ & $\begin{array}{l}\text { New apparent power flow between bus } i \\
\text { and bus } j \text { after compensation }\end{array}$ \\
\hline $\cos \left(\phi_{0}\right)$ & Power factor before compensation \\
\hline $\cos \left(\phi_{n}\right)$ & Power factor after compensation \\
\hline KI & Loading factor \\
\hline$I_{C \max }$ & Maximum capacitive current \\
\hline$I_{L \max }$ & Maximum inductive current \\
\hline$\alpha_{\max }, \alpha_{\min }$ & Maximum and minimum firing angle \\
\hline$V_{\text {ref }}$ & Reference voltage \\
\hline
\end{tabular}

Abbreviations

FACTS

STATCOM

$\mathrm{RD}$

RS

PV

TSA

RPP

RPD

SW

TW

PF

BPSO

STATCOM
A flexible alternating current transmission system

Static synchronous compensator

Radial distribution.

Renewable source

Photovoltaïque source

Tree seed algorithm

Reactive power planning

Reactive power dispatch

Sectionalizing switch

Tie switch

Power flow

Binary Particle Swarm Optimization

Static synchronous compensator

\section{D-STATCOM Distributed static synchronous compensator \\ OLTC On-Load Tap Changer}

\section{Introduction}

Ensuring reliable operation of modern radial distribution (RD) systems is a vital challenge for utility companies and experts specialized in power system planning and operation. Due to the economic aspect, most electrical distribution systems have radial structure. This topology has low investment cost, easy to dispatch and power system protection is not complex. Otherwise, the operation of radial topology without adequate energy management cannot guaranty sufficient energy quality and service continuity in particular at critical situations such as load growth and faults. Recently with large diffusion in electricity market of flexible ac transmission system (FACTS) and various types of renewable sources such as wind energy, solar energy and fuel cell sources, the modern distribution power system becomes more flexible to control and to dispatch, which allows improving the quality of energy and service continuity [1]. Otherwise, the main drawback of integration of various types of renewable sources such as wind and PV sources in RD systems is related to their intermittent behavior. The integration of renewable sources needs robust planning strategies to improve the performance of RD systems in terms of reduction of total power losses, improvement the voltage magnitudes and improvement the margin reserve security [2].

In the literature, various planning strategies based on analytical methods, metaheuristic and hybrid methods have been developed and used to improve the performances of modern radial distribution systems considering the integration of various types of renewable sources [3]. These developed techniques have been applied to solve three categories of optimal planning of RD systems. The first research target has been oriented to find the optimal allocation and size of conventional bank capacitors [3] in RD systems. The second research objective is investigated to optimize the size and location of distribution generation (DG) in coordination with bank compensators $[3,4]$, and finally, the third target focuses on the optimal reconfiguration of modern radial distribution systems by optimizing the number and location of multi-switch to be operated in the presence of multi-DG and shunt compensators [5]. Among these techniques, authors in [6] applied a novel approach based on crow search algorithm for optimal selection of conductor size in radial distribution networks, in [7] a mixed integer nonlinear programming approach is applied to solve the optimal location of bank capacitors in radial distribution systems, in [8] an analytical 
approach is applied to solve the optimal location of distributed generation and bank capacitors for power loss minimization, in [9] a hybrid heuristic search optimization technique is applied to solve the optimal location and size of distributed generators and shunt compensators, in [10] a selective firefly algorithm is applied to solve the distribution network reconfiguration to minimize total power loss, in [11] a multi-objective evolutionary algorithm based on decomposition (MOEA/D) is adapted to select optimal sizes and locations of DGs and shunt compensator in large scale RD networks, in [12] an interactive methodology is applied to solve the optimal placement of multi-periodbased switched capacitor in radial distribution electric system, in [13] an improved selective binary particle swarm optimization (BPSO) is applied to solve the network reconfiguration for loss reduction, in [14] an improved shuffled frog leaping is used to solve the reconfiguration problem in radial distribution system in the presence of multi-distributed generation (DG), the impact of reconfiguration strategy on the power loss reduction in practical radial distribution system is well demonstrated in [15]. Considered as a new research direction, authors in [16] applied fast metaheuristic algorithms for optimal reconfiguration in radial distribution system to reduce the number of harmonics. In [17] a hybrid planning strategy reduction in radial distribution system based on the reconfiguration procedure and optimal control of On-Load Tap Changers (OLTCs), Distributed generation (DG), and Distributed static synchronous compensator (D-STATCOM) for power loss minimization and voltage deviation. In [18] a differential evolution (DE) is applied to solve the multi-objective optimal power flow considering the integration of Wind sources in coordination with STATCOM devices, and in [19], a probabilistic power flow strategy is proposed to solve single and multi objective based power loss and voltage deviation in the presence of photovoltaic distributed generators, in [20] a fully distributed reactive power optimization and control method for active distribution networks, in $[21,22]$, a distributed control algorithm is proposed for optimal reactive power control in power grids, in [23] three recent metaheuristic methods such as Grey Wolf, Dragonfly and Moth-Flame Algorithms have been successfully adapted and applied for optimal sizing and placement of capacitors in RD systems, in [24] a Flower Pollination Algorithm and Loss Sensitivity Factors is proposed to solve the optimal sizing and allocation of capacitors banks in RD systems, the main objective function considered is only the total power loss, in [25] a recent algorithm named Polar Bear Optimization Algorithm is successfully adapted and applied to solve the optimal allocation and sizing of conventional compensators based shunt capacitors in RD systems, the main objective function treated is the minimization of total power loss at normal exploitation, in [26] the allocation problem of multi shunt compensators is solved using hybrid method based on analytical and two metaheuristic optimization techniques, in [27], a recent method named chaotic quasi oppositional chemical reaction optimization is applied to solve the reconfiguration of shunt compensators, in [28] a gravitational search algorithm is also applied to solve the allocation problem of shunt compensators, and in [29] an improved atom search optimization is used to solve size and allocation of multi distributed shunt compensators. Authors in [30] proposed a highly relevant technique to find the optimal location of a shunt compensator namely synchronous compensator (STATCOM) based FACTS technology to dampen the rotor angle oscillations and enhance the transient stability of multi machine systems.

Based on the statistical analysis of several optimization methods cited in the recent literature used to improve the performances of RD systems, it is found that the most of these methods are oriented to optimize the performances of RD systems at normal condition, second, various objective functions related to practical planning problems such as total power loss, the margin reserve, the reconfiguration process, allocation and sizing problems of shunt compensators are not treated in coordination. Optimal setting and sizing of multi-conventional compensators and shunt compensators based FACTS devices such as SVC and STATCOM, it is mandatory to consider critical operation of RD systems such as the critical load growth and severe faults.

In this paper a new optimization variant based treeseed algorithm (TSA) recently proposed by M. S. Kiran [31] is adapted and applied to improve the performance of RD systems in terms of reduction of the total power loss, minimization of voltage deviation and improving margin reserve. To exploit efficiently the performances of radial distribution system in particular under critical load growth, a reactive power-planning strategy based STATCOM devices has been applied in coordination with the reconfiguration operation. It is found that reactive power control in the distribution system may be considered an important strategy to ensure service continuity and economic exploitation. The contributions of this paper are summarized as follows:

1. A novel variant based TSA is proposed to solve the reactive power dispatch and network reconfiguration in $\mathrm{RD}$ system.

2. In this study, the setting and sizing of multi STATCOM devices and multi PV sources are considered

3. The reactive power dispatch of multi STATCOM devices is optimized in coordination with multi PV sources at normal exploitation and considering critical load growth. 
4. Total power loss and margin reserve are two objective functions considered and optimized at normal condition and under load growth.

The paper is organized as follows: a brief review of the development and application of various metaheuristic methods in solving several problems related to power system planning and control is given in Sect. 1. Descriptions of RD and optimization formulation are introduced in Sect. 2. In Sect. 3, the basic principle of reactive power compensation is presented. Models of PV source and STATCOM devices are described in Sect. 4. The proposed TSA technique is detailed in Sect. 5, the obtained results are recapitulated and discussed in Sect. 6, and finally, useful conclusion and perspective work directions are given in Sect. 7.

\section{Radial Distribution Eclectic Network}

\subsection{Overview}

The well known the topology of the RD electric system has a simple structure and consists of one source named substation, one principal feeder and at least one derivation.

As well shown in Fig. 1, the voltage magnitude decreases toward end of the feeder, as the impedance of lines causes a voltage drop. Thus, for this simple topology, the weak bus with low voltage magnitude is located at the end of the feeder [1].

\subsection{Basic power flow equations}

\subsubsection{Power loss in lines}

The generalized formulas for active and reactive power loss in line located between bus $k$ and bus $k+1$ are calculated using the following simplified equations [1]:

$P_{\text {loss }}(k, k+1)=\left(\frac{P_{k, k+1}^{2}+Q_{k, k+1}^{2}}{\left|U_{k}\right|^{2}}\right) \cdot R_{k, k+1}$

$Q_{\text {loss }}(k, k+1)=\left(\frac{P_{k, k+1}^{2}+Q_{k, k+1}^{2}}{\left|U_{k}\right|^{2}}\right) \cdot X_{k, k+1}$

\subsubsection{Total power losses}

The total real power loss of the RD electric system can be easily found by summing all the branches power loss and it is expressed as:

$P_{t, \text { loss }}=\sum_{k=1}^{n b r} P_{\text {loss }}(k, k+1)$

\section{Optimization Tasks}

The main objective of the proposed optimal planning strategy is to optimize the locations and sizes of multiPV sources based renewable energy and multi-STATCOM devices to improve the performance of RD systems. The objective functions adopted in this study are the reduction
Fig. 1 Simple structure of radial distribution electric system

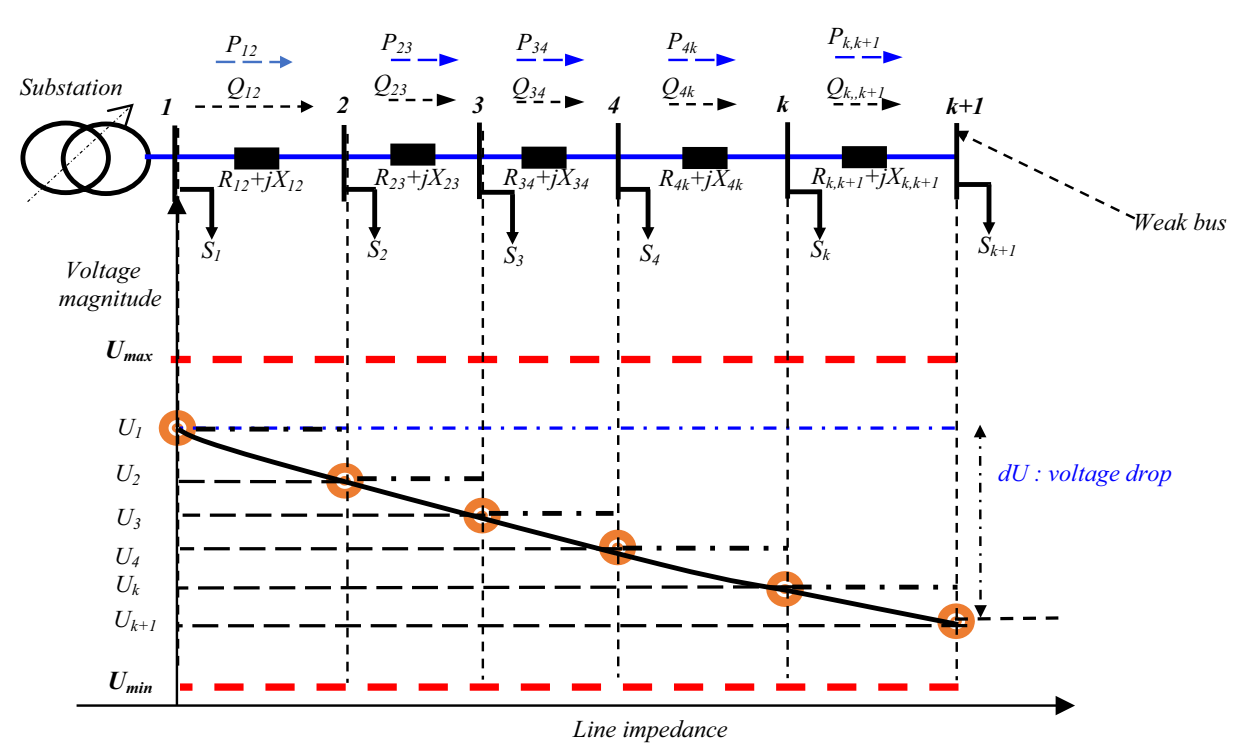


of active power losses and improving the margin reserve of the RD electric network while considering all security and operation constraints.

\subsection{Objective functions}

In this study, two objective functions are considered, the total power losses and the margin reserve of the RD electric network, these two objective functions are optimized considering all security constraints.

\subsubsection{Minimization of total power loss}

Obj1 $=f_{\text {loss }}=\operatorname{Min}\left(P_{t, \text { loss }}=\sum_{k=1}^{n b r} P_{\text {loss }}(k, k+1)\right)$

\subsubsection{Maximization of margin reserve (MR)}

To ensure reliable exploitation and operation of modern $\mathrm{RD}$ in particular at critical situations such as load growth and faults, it is mandatory to reduce the reactive power transit in different branches. This objective function optimizes the reactive power flow in all branches to maximize the margin reserve of the principal transformer located at the substation and improving he MR of the large number of dispersed transformers (30/0.4 kV). The expression of this objective function is formulated as follows:

$\operatorname{Obj2}=M R=\max \left(\frac{\operatorname{real}\left(\sum_{k=1}^{N I} I_{k}\right)}{\operatorname{imag}\left(\sum_{k=1}^{N I} I_{k}\right)}\right)$

where, $M R$ is the margin reserve, $I_{k}$ is the current delivered to load at bus $k$, and $N I$ is the number of load.

The lower reactive current delivered by the substation causes a higher margin reserve of the RD network. The reduced value of reactive current allows the substation to deliver supplementary active power to consumers with an admissible power quality in particular at critical situations such as faults and load growth.

\subsection{Constraints}

\subsubsection{Equality constraints}

The basic active and reactive power balancing constraint is expressed by the two following expressions:
$P_{t r, s l a c k}+\sum_{i=1}^{N p v} P_{p v, i}=\sum_{i=1}^{N l} P_{D, i}+\sum_{m=1}^{n b r} P_{l o s s, m}$

$Q_{t r, s l a c k}+\sum_{i=1}^{N p v} Q_{p v, i}=\sum_{i=1}^{N l} Q_{D, i}+\sum_{m=1}^{n b r} Q_{l o s s, m}$

\subsubsection{Inequality constraints}

The inequality constraints represent the security constraints related to the elements of the network distribution system.

\subsubsection{Voltage constraint}

The following expression represents the limits on voltage magnitudes at all buses

$V_{i}^{\min } \leq V_{i} \leq V_{i}^{\max }, i=1,2, \ldots$, Nbus

\subsection{Renewable source constraints}

The decision variables of various renewable sources (RS) used must be allowable in the range of size and power factor. For solar source the active power is restricted as follow:

$P_{p v, i}^{\min } \leq P_{p v, i} \leq P_{p v, i}^{\max }, i=1,2, \ldots, N p v$

- Maximum level of RS penetration:

The amount of active power to be injected in the network by RS is called the level of penetration of RS [1, 2]. In general, the constraint related to the penetration level is calculated as follows:

$\sum_{i=1}^{N p v} P_{p v, i} \leq \mu \sum_{j=1}^{N l} P_{D, j}$

where, $\mu$ is the penetration level.

- STATCOM constraints: the reactive power of STATCOM device integrated at bus $i$ must be restricted within its admissible limit.

$Q_{S t c, i}^{\min } \leq Q_{S t c, i} \leq Q_{S t c, i}^{\max }$

- Line current flow:

All the currents transit in lines must be maintained below their admissible value.

$I_{b r i} \leq I_{b r i}^{\max }$ bri $=1 \ldots . . . n b r$ 


\section{Principle of Reactive power compensation}

The following steps explain the effect of reactive power compensation on voltage regulation and improvement of power factor using simplified linear mathematical equations. Figure 2 shows the basic principle of reactive power compensation.

1. Before compensation: The voltage drop between bus $i$ and bus $j$ before compensation is given as follow:

$d U_{i j}=\frac{P_{i j} \cdot R_{i j}+Q_{i j} \cdot X_{i j}}{U i}$

2. After compensation: in order to improve the voltage magnitude at bus j, a specified value of reactive power is injected by the shunt compensator in bus j. The new expression of voltage drop magnitude is expressed as follows:

$$
\begin{aligned}
& d U_{i j}^{c}=\frac{P_{i j} \cdot R_{i j}+Q_{i j}^{c} \cdot X_{i j}}{U i}=\frac{P_{i j} \cdot R_{i j}+\left(Q_{i j}-Q_{S t c}\right) \cdot X_{i j}}{U i} \\
& d U_{i j}^{c}=\frac{P_{i j} \cdot R_{i j}+Q_{i j} \cdot X_{i j}}{U i}-\frac{Q_{S t c} \cdot X_{i j}}{U i}=d U i j-d U_{c} \\
& d U_{c}=\frac{Q_{S t c} \cdot X_{i j}}{U i}
\end{aligned}
$$

where, $d U_{c}$ is the corrected voltage magnitude introduced by the compensator.
As well expressed in the expression (Eq. 16), the desired voltage magnitude to be controlled depends on the amount of reactive power to be exchanged with the electric network.

\section{PV source and STATCOM controller modeling}

\subsection{PV source modeling}

The PV source is an important type of renewable sources, largely used and integrated in many practical power systems. The PV can deliver only active power to the network. Like various renewable sources, the PV source has an intermittent aspect, which is considered as the major inconvenient of renewable sources. For this pertinent reason, the integration of $\mathrm{PV}$ source requires robust planning strategy based on active power dispatch in coordination with reactive power support. Figure 3 shows the basic model of PV source.

\subsection{STATCOM controller modeling}

STATCOM is one of the recent generation of the shunt FACTS devices commissioned and firstly installed in 1999 in a practical power system [19]. The STATCOM consists of voltage source converter build with Thyristors with turnoff capability, a coupling transformer, a DC capacitor, and controller unit [30]. The STACOM device can generate or absorb reactive power to control the voltage at a specified bus. Firstly the main effect of STATCOM devices integrated

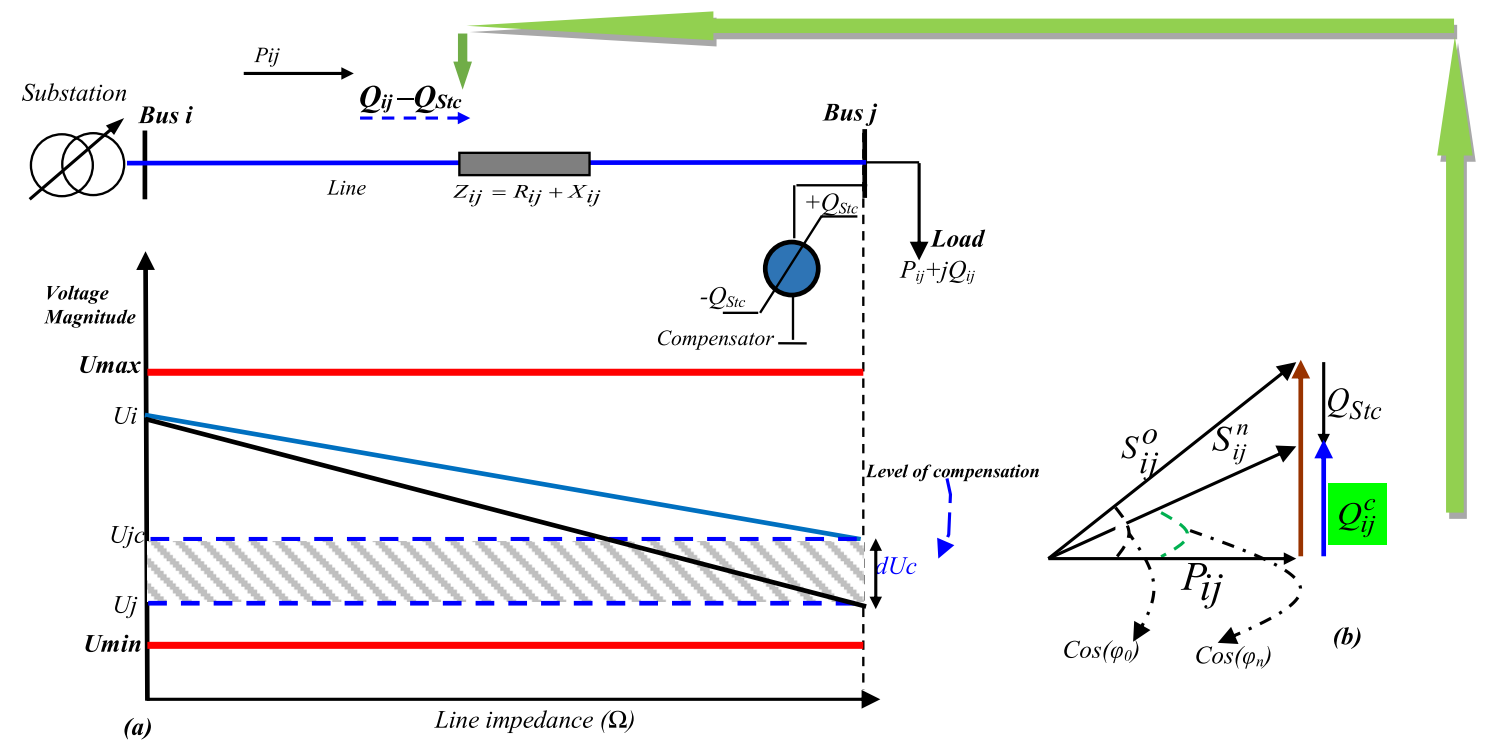

Fig. 2 Principle of shunt compensation: (a) Voltage regulation, (b) Power factor correction 


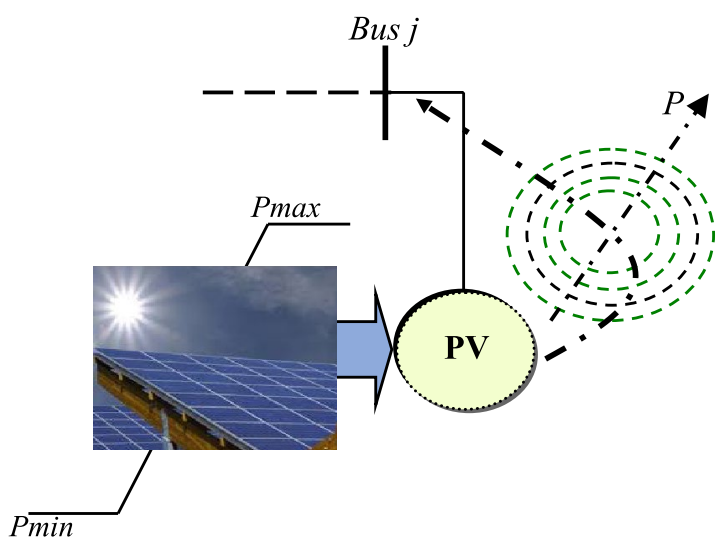

Fig. 3 Simplified model of PV source

at specified location is to ensure fast reactive power control with the network [32]. Secondly, the STATCOM controller designed especially for shunt compensation has a better ability to deliver the maximum reactive power at critical situations such as severe contingencies and low voltage magnitudes. The reactive power control based STATCOM is more efficient than using SVC device and conventional compensators. The structure of STATCOM controller is shown in Fig. 4, the model of STATCOM is shown in Fig. 4a, and its steady state voltage-current characteristic is shown in Fig. 4b.

\subsection{STATCOM modeling in power flow algorithm}

An alternative way to model the STATCOM in the power flow algorithm is described in [19]. The generalized active and reactive power equations related to STATCOM power flow model are formulated as follows:

$P_{S t c}=V_{k}^{2} \cdot g_{S t c}+V_{k} \cdot V_{S t c}\left(g_{S t c} \cdot \cos \left(\delta_{S t c}-\delta_{k}\right)+b_{S t c} \cdot \sin \left(\delta_{S t c}-\delta_{k}\right)\right)$

$Q_{S t c}=-V_{k}^{2} \cdot b_{S t c}+V_{k} \cdot V_{S t c}\left(g_{S t c} \cdot \sin \left(\delta_{S t c}-\delta_{k}\right)-b_{S t c} \cdot \cos \left(\delta_{S t c}-\delta_{k}\right)\right)$

where, $v_{k}$, is the voltage at bus $k$ and $V_{\text {Stc }}$ is the voltage delivered by STATCOM, $\left(\delta_{S t c}-\delta_{k}\right)$ is the difference angle between the two voltages, $g_{S t c}, b_{S t c}$ are the conductance and the susceptance of the STATCOM respectively. Based on Fig. $4, \mathrm{c}$ ), it is found that the STATCOM has a robust characteristic compared to SVC device to deliver the maximum reactive power at low voltages. In this situation the STATCOM can operate in two modes:

- Capacitive mode: if $V_{S t c}>V_{k}$, the STATCOM operates in capacitive mode, and delivers reactive power to the network.

- Inductive mode: if $V_{S t c}<V_{k}$, the STATCOM operates in inductive mode, and absorbs reactive power from the network.

\section{Optimization method based tree-seed algorithm}

TSA is a novel optimizer introduced recently by M.S Kiran [31]. The proposed method is based on relation between trees and there seeds. The TSA is simple to program and to adapt and offers the ability to create flexible balance between the intensification and diversification during

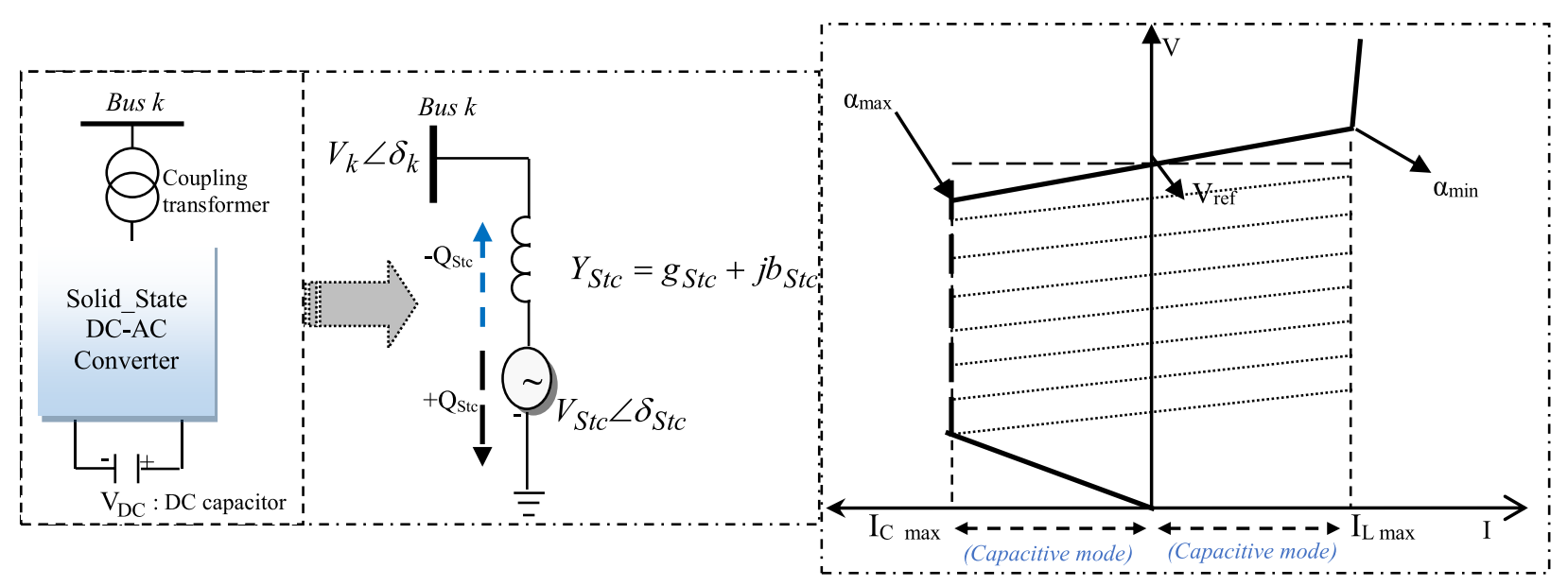

(a)

(b)

Fig. 4 Structure of STATCOM: (a) Model of STATCOM, (b) Voltage-current characteristic of STATCOM 
search process. The basic mechanism search of TSA is shown in Fig. 5.

\section{- Algorithm description}

It is well known, that in nature, trees spread to the surface through their seeds. Each tree has its associated seeds, theses seeds grow over time and new generation of trees is formed to succeed the original trees. The interaction aspect between trees and their succeeded seeds may be relatively interpreted in mathematical form as follows:

- Firstly, the initial locations of trees are generated randomly and considered as a possible solution to the problem. Trees are assimilated to population term and associated to specified control variables. As well known, the traditional formula used to generate the initial population is given as:

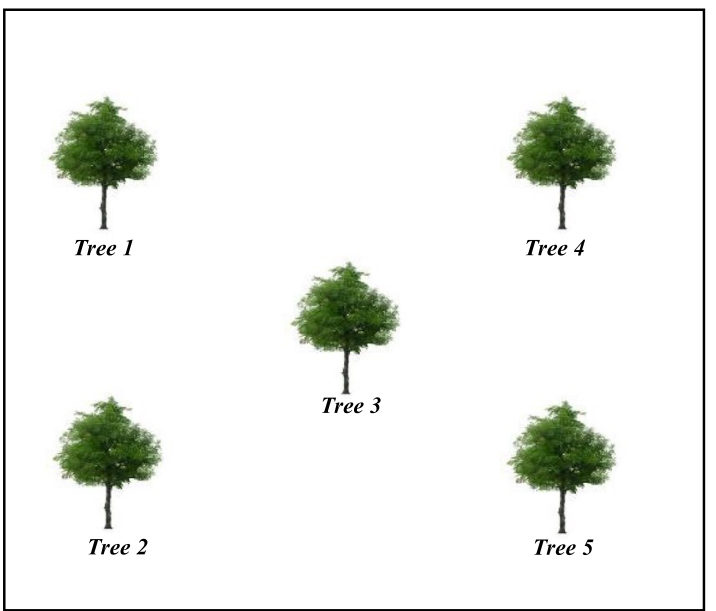

(a)
$T_{i j}=L_{j, \min }+r_{i j}\left(H_{j, \max }-L_{j, \min }\right)$

where $L_{j, \text { min }^{\prime}} H_{j, \text { max }}$ are the minimum and maximum values of decision variables respectively, $r_{i j}$ is a random number in the range [0 1].

- The location of trees and seeds may be considered a candidate solution to an optimization problem. The possible location of various seeds produced from a tree is an important process. For this pertinent reason, the evolution of tress and seeds during the search process is exploited and generated using the following search equations:

$S_{i j}=T_{i, j}+\alpha_{i j} \times\left(B_{j}-T_{r, j}\right)$

$S_{i j}=T_{i, j}+\alpha_{i j} \times\left(T_{i, j}-T_{r, j}\right)$

where, $S_{i j}$ is the jth dimension of ith seed designed to produce $i$ th tree, $T_{i, j}$ is the $j$ th dimension of $i$ th tree,

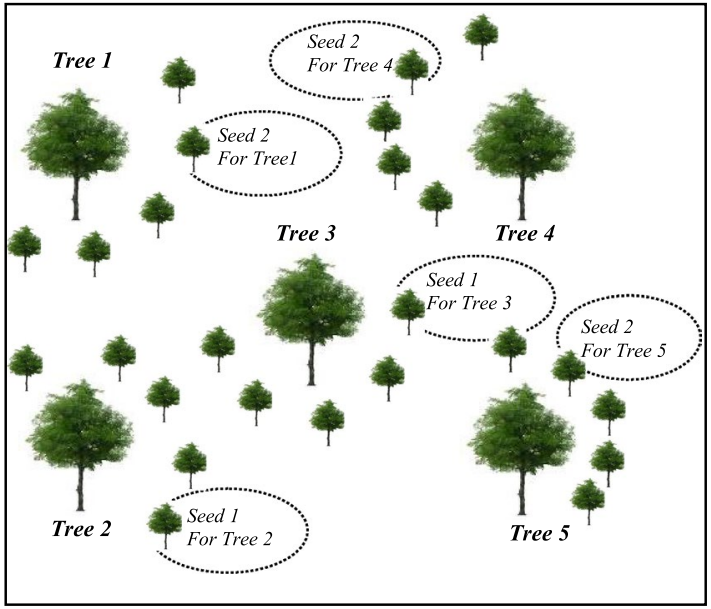

(b)

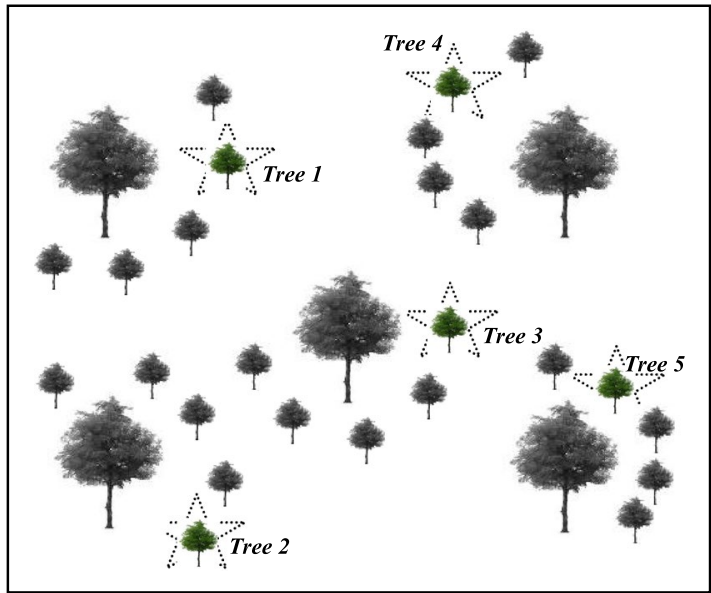

(c)

Fig. 5 Basic mechanism search of TSA: (a) initial search space, (b) production of seeds, (c) new location of trees 
$B_{j}$ is the $j$ th dimension of best tree location, $T_{r, j}$ is the $j$ th dimension of $r$ th tree randomly selected from the population. $\alpha$ is a scaling factor randomly generated in the range $\left[\begin{array}{ll}-1 & 1\end{array}\right]$.

The first equation (Eq. 20) considers the tree location that the seed will be produced for this tree and the best location of the tree population.

The second equation (Eq. 21) uses two different tree locations for producing a new seed for the tree.

During search process, one of the two equations (Eq. (20), Eq. (21)) may be selected to produce a new seed location. The selection is based on a control parameter named a search tendency (ST), the value of ST is randomly generated in the range [0 1], the higher value of ST provides an efficient local search; while small value of ST causes a powerful global search process.

- Finally, the best solution is obtained from the population, and using the following equation:

$$
B=\min \left\{f\left(\vec{T}_{i}\right), i=1,2, \ldots \ldots . . . N_{\text {tree }}\right\}
$$

where, $N_{\text {tree }}$ is the population size, the detail steps of the original algorithm are given Fig. 6 .

- Proposed planning strategy based TSA

Based on the flowchart shown in Fig. 7, the steps of the proposed planning strategy are summarized as follows:

1. Introduce all technical data of the RD electric network

2. Introduce the initial parameters of the TSA, in this study, the population is taken between 10 and 20 trees, ST equal 0.1, and the maximum number of generation is taken between 80 and 100, it depends on the size of the problem to be solved.

3. Run power flow to find the initial state of the network

4. Introduce the type of objective function to optimize, two objective functions have been considered, the minimization of total power loss and maximization of margin reserve security.

5. Find the best location of shunt compensators and PV sources based on sensitivity index.

6. Introduce the desired loading factor

7. At trail 1, run TSA, save the optimized results
Fig. 6 Stages of the standard TSA
Stage 1: Initialize the parameters of the TSA algorithm.

- Specify the number of population size (Npop).

- Specify the value of ST parameter

- Specify the dimension of the problem (Nvars)

- Specify the convergence criterion: maximum number of generation (Gmax).

- Generate N random tree location using Eq. 19.

- Evaluate the tree location using the fitness function associated to the problem.

- $\quad$ Select the best solution using Eq. 22.

Stage 2: Begin search with Seeds

FOR all trees

Specify the number of seeds produced for this tree.

FOR all seeds

FOR all dimensions

IF $($ rand $<$ ST)

Update this dimension using Eq. 20

ELSE

Update this dimension using Eq. 21

END IF

END FOR

$\checkmark$ END FOR

Select the best seed and compare it with the tree

If the seed location is better than tree location, the seed substitutes for this tree.

$\checkmark$ END FOR

Stage 3: Select the best solution of population.

If new best solution is better than the previous best solution, new best solution substitutes for the previous best solution.

Stage 4: Check the convergence criterion

If the criterion condition is not reached, go to Step 2 .

Stage 5: Report the best solution 
Fig. 7 Flowchart of the proposed planning strategy based TSA

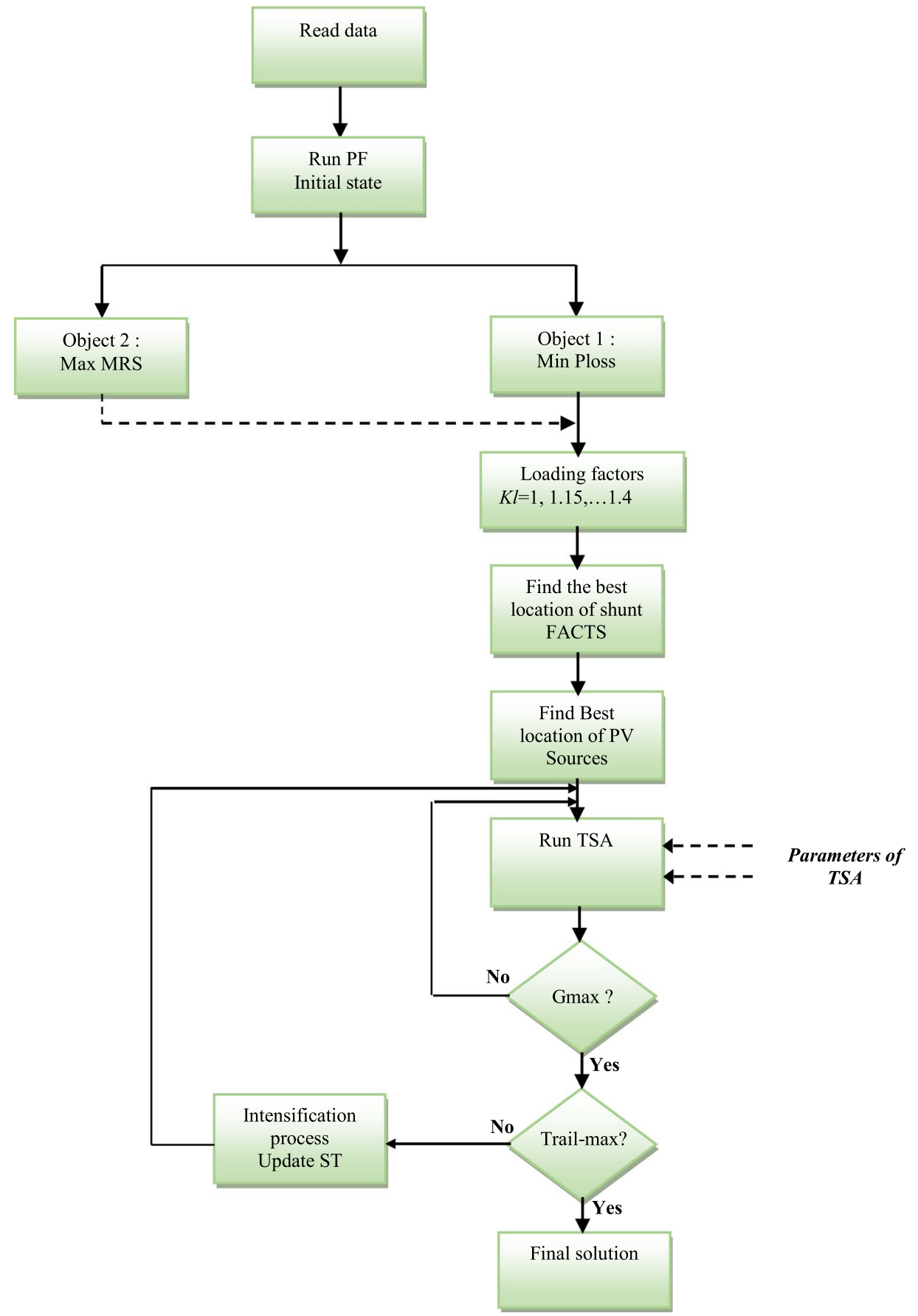

8. For trail >1: Execute intensification process: run TSA based on an updated population: initial_population = best_pop_trail1. After the first trail, the mechanism search will be oriented to execute intensification phase to well locate the near global solution and to escape from the local optimal solution.

8.1 The ST parameter is randomly adjusted to a high value to provide an efficient local search (intensification), the value of ST is adjusted to: ST = ST (old) + rand/Itmax
8.2 If the new best solution achieved is not improved, then the process search will be oriented to bascule again to the exploration stage, ST = ST (old)-rand/Itmax

8.3 Repeat all steps until the maximum number of trail is achieved

9. Save the final optimized results. 


\section{Cases analysis}

Electric test system 1: Radial distribution system 33-buses.

This first test system consists of 32 lines and 33 buses, the RD 33-Bus has a voltage of $12.66 \mathrm{kV}$, the apparent power to satisfy at normal condition is $(3.715+\mathrm{j} 2.300)$ MVA.

Case 1: Optimal exploitation under normal condition considering one STATCOM device.

Scneario 1: The main objective of this first case is to optimize the total power losses by optimizing the reactive power of multi STATCOM exchanged with the network. Due to the economic aspect associated to STATCOM device, it is important to determine the size and number of STATCOM devices to be installed. For this pertinent reason, four STATCOM are used and located at buses $(10,18,25$, and 30$)$, using sensitivity index [1, 2]. The initial sizes of STATCOM devices are taken in the range [- 1.5 1.5] MVAR. First, the four STATCOM devices are integrated individually, as well depicted in Table 1 , the best optimized power loss $(0.1436 \mathrm{MW})$ is found by installing compensator at Bus 30 , the critical value of voltage magnitude is $0.9131 \mathrm{p.u}$, the value of reactive power exchanged between the STATCOM and network is 1.2527 MVAR. Second, the four compensators are considered simultaneously. For this scenario, the total power loss is reduced to $\mathbf{0 . 1 3 1 7 8 4} \mathrm{MW}$. The voltage magnitude is improved to 0.9407 p.u, the total reactive power of the four STATCOM devices optimized is $\mathbf{1 . 9 0 0 9}$ MVAR. Figure 8 shows the convergence characteristics for power loss minimization based on one compensator at loading factor $K I=1$.

Scenario 2: This scenario is investigated to optimize the total power loss and the total size of multi-STATCOM devices. For fair comparison with other techniques treating the same problem, only three STATCOM devices have been integrated in buses: 10, 18 and 30 . By considering the total size of compensators, the total power loss

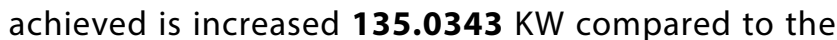
scenario 1 , and the optimized total size of STATCOM devices is reduced from 1900.9 KVAR to 1543.70, which is better and competitive compared to values found by all other techniques such as, Genetic Algorithm (GA), Plant Growth Simulation Algorithm (PSGA), Gravitational Search Algorithm (GSA), Simulated Annealing (SA), Interior Point (IP), Flower Pollination Algorithm (FPA), Moth Flame Optimization (MFO) Algorithm and grey wolf Optimization (GWO) Algorithm. The results obtained using the modified TSA, prove its flexible ability to locate with accuracy the near compromise optimal solution for power loss and the total size of multi distributed STATCOM compensators. The proposed technique may be suitable to solve various combined problems related to power system operation and control. Table 2 shows a comparative study between the proposed modified TSA and other recent techniques. The convergence behavior for power loss minimization considering the total size of multi distributed STATCOM devices is shown in Fig. 9.

Case 2: Optimal exploitation under load growth considering only one STATCOM device

The main task of this case is to determine the capability of one STATCOM device to improve the performance of RD system in terms of total power loss and minimum voltage magnitude. As well depicted in Table 3 , at the loading factor 1.15 , the best total power loss achieved is $(\mathbf{0 . 1 9 6 1} \mathrm{MW})$ by installing one STATCOM at bus 30 which injects 1.1633 MVAR. The low voltage magnitude is $\mathbf{0 . 9 1 0 9}$ p.u. The worst total power loss achieved is obtained by installing the STATCOM at bus 25 .

Case 3: Optimal exploitation under load growth considering four STATCOM devices

In this case, four STATCOM devices have been investigated to optimize the total power loss at various loading factors (1.15, 1.3 and 1.4). As well depicted in Table 4, the four compensators allow RD system to

Table 1 Optimized RD performances under normal condition: integration one and four STATCOM devices

\begin{tabular}{|c|c|c|c|c|c|c|}
\hline & STATCOM Location & & & & & \\
\hline & Without STATCOM & 10 & 18 & 25 & 30 & $10-18-25-30$ \\
\hline PT (MW) & 3.9177 & 3.8849 & 3.8975 & 3.9075 & 3.8586 & 3.8468 \\
\hline QT (MVAR) & 2.4352 & 1.4820 & 1.9374 & 1.6993 & 1.1436 & 0.4871 \\
\hline PLoss (MW) & 0.2027 & 0.1699 & 0.1825 & 0.1925 & 0.1436 & 0.131784 \\
\hline Vmin (p.u) & 0.9131 & 0.9256 & 0.9213 & 0.9146 & 0.9256 & 0.9407 \\
\hline Vstc (p.u) & / & 0.9524 & 0.9428 & 0.9788 & 0.9523 & $0.9519-0.9407-0.9779-0.9520$ \\
\hline Size of STATCOM devices (MVAR) & / & 0.9324 & 0.4860 & 0.7308 & 1.2527 & $0.3392,0.1284,0.4200,1.0133$ \\
\hline Total size of STATCOM devices & & 0.9324 & 0.4860 & 0.7308 & 1.2527 & 1.9009 \\
\hline Loss reduction (\%) & & 16.18 & 9.97 & 5.03 & 29.16 & 34.73 \\
\hline Loading factor: $K I$ & 1 & 1 & 1 & 1 & 1 & 1 \\
\hline
\end{tabular}

Bold format in tables indicate the best values achieved 
Fig. 8 Convergence characteristics for power loss minimization based one compensator at loading factor $K I=1$
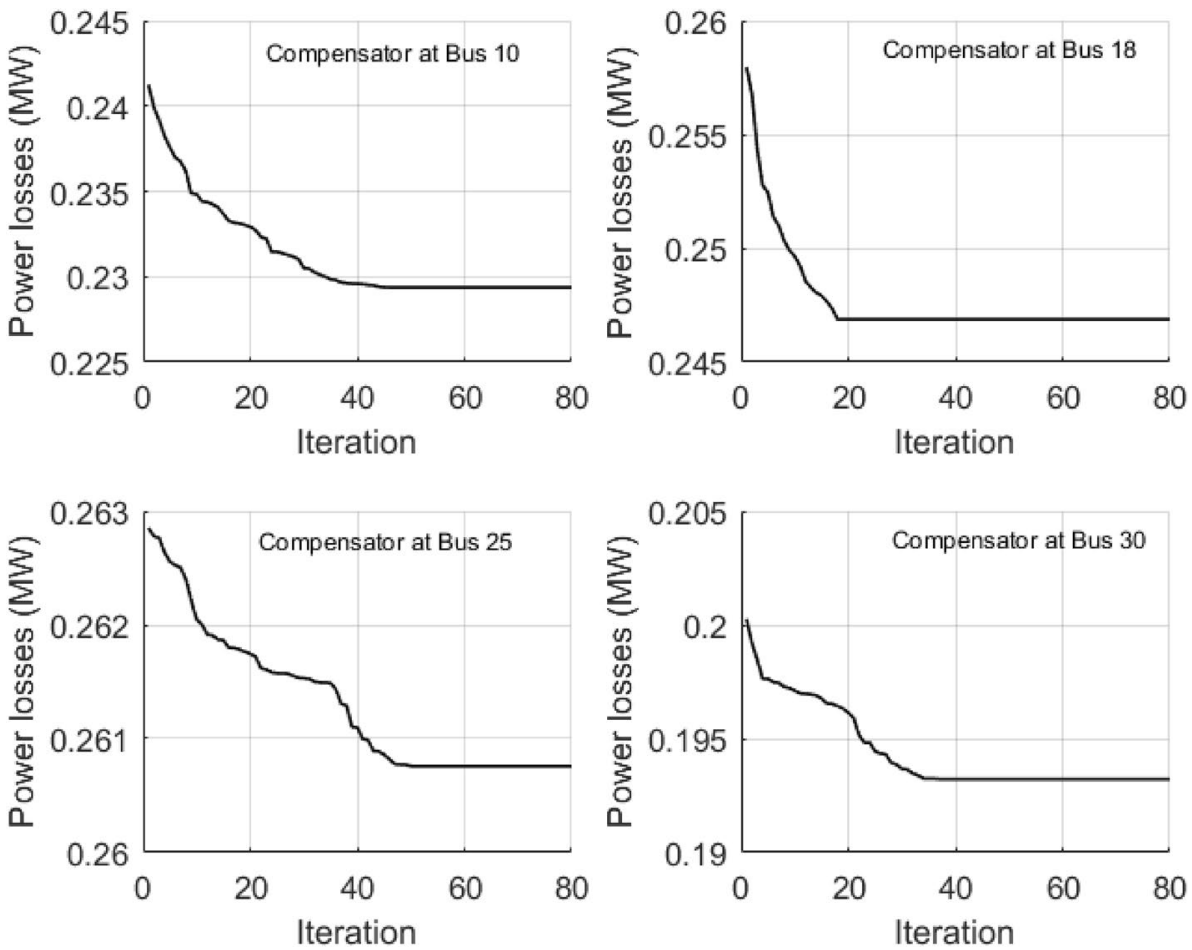

maintain adequate power quality at high load growth. The total power loss achieved at high loading factor 1.4 is $\mathbf{0 . 2 7 0 9} \mathrm{MW}$, the required reactive power of STATCOM devices installed at buses $10-18-25$ and 30 are [0.5829-0.1805-0.6283-1.1961] respectively. Figure 10 shows the convergence characteristics for power loss minimization based four compensators at loading factors: $1-1.15,1.3$ and 1.4 .

Case 4: Optimal exploitation under normal condition considering renewable PV sources and STATCOM devices:

In this case, two scenarios are treated. In the first scenario, four PV sources and four STATCOM devices are installed at buses 10-18-25-30. The limits of PV sources are in the range [0 1] MW. The initial sizes of all STATCOM devices are taken in the rage [-1 1 ] MVAR. By considering the total power loss as the main objective function, the values of the optimized active power loss at various penetration level are $(\mathbf{0 . 0 1 3 5}, \mathbf{0 . 0 1 7 2}, \mathbf{0 . 0 3 0 5}, \mathbf{0 . 0 5 3 5}$, and $\mathbf{0 . 0 8 7 0}$ ) MW, respectively. As well depicted in Table 5, the total power loss is reduced at high level penetration (67.2947\%). The voltage control of four STATCOM devices at a high level penetration is $(0.9923,1,0.9862$, and 0.9919$)$. Figures 11 and 12, show the convergence characteristics of power loss minimization at all penetration level. Figure 13 shows the distribution of voltage magnitudes at all buses. As well shown in Figs. 11 and 12, the near optimal solution is obtained at a reduced number of iterations, less than 5 trials are necessary to locate the best solution. In the second scenario and for fair comparisons with other recent techniques, the total power loss is optimized considering only the integration of four PV sources. As well shown in Table 6, the total power loss increased compared to the first scenario, this proves the importance of coordination between STATCOM devices and PV sources to reduce the total power loss. In order to validate the efficiency of the proposed TSA, results found have been compared to various recent optimization methods such as PSO, dynamic adaptation of PSO (DAPSO), Backtracking search optimization algorithm (BSOA), Improved analytical method (IA) and Multi objective PSO (MOPSO) [19]. Table 7 recapitulate a comparative study with other methods for power loss minimization at normal condition. The optimized active power loss achieved using the proposed TSA is $73.3 \mathrm{~kW}$,

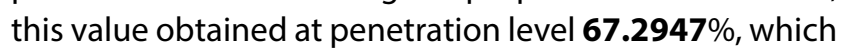
is better and competitive than that obtained using other methods, except the PSO (71.64 kW). However, it is important to note that the optimal power loss obtained by PSO [19] at high penetration level (78.73\%), and at penetration level of $105.86 \%$ by using MOPSO [19]. Due to the intermittent and stochastic aspect of PV sources, the integration level of renewable sources must be limited within an admissible security value to ensure suitable margin stability and service continuity of the network.

Case 5: Optimal exploitation considering load growth based PV sources and STATCOM devices:

In this case, four PV sources and four STATCOM devices are installed and controlled to minimize the total power loss under load growth $(K I=1.4)$. The limits of PV sources 

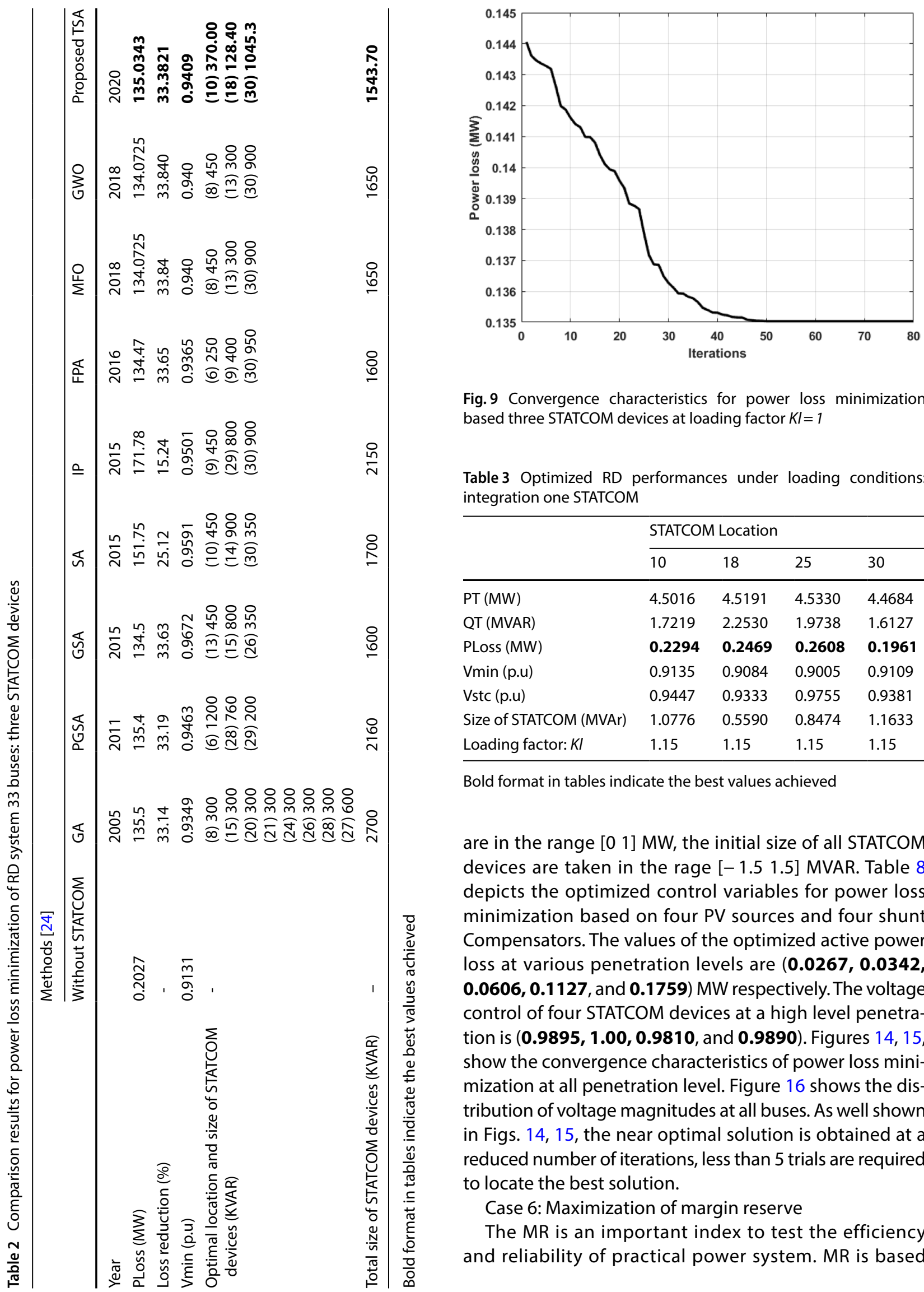

Fig. 9 Convergence characteristics for power loss minimization based three STATCOM devices at loading factor $K I=1$

Table 3 Optimized RD performances under loading conditions: integration one STATCOM

\begin{tabular}{lllll}
\hline & \multicolumn{4}{l}{ STATCOM Location } \\
\cline { 2 - 5 } & 10 & 18 & 25 & 30 \\
\hline PT (MW) & 4.5016 & 4.5191 & 4.5330 & 4.4684 \\
QT (MVAR) & 1.7219 & 2.2530 & 1.9738 & 1.6127 \\
PLoss (MW) & $\mathbf{0 . 2 2 9 4}$ & $\mathbf{0 . 2 4 6 9}$ & $\mathbf{0 . 2 6 0 8}$ & $\mathbf{0 . 1 9 6 1}$ \\
Vmin (p.u) & 0.9135 & 0.9084 & 0.9005 & 0.9109 \\
Vstc (p.u) & 0.9447 & 0.9333 & 0.9755 & 0.9381 \\
Size of STATCOM (MVAr) & 1.0776 & 0.5590 & 0.8474 & 1.1633 \\
Loading factor: KI & 1.15 & 1.15 & 1.15 & 1.15 \\
\hline
\end{tabular}

Bold format in tables indicate the best values achieved

are in the range [0 1] MW, the initial size of all STATCOM devices are taken in the rage [-1.5 1.5] MVAR. Table 8 depicts the optimized control variables for power loss minimization based on four PV sources and four shunt Compensators. The values of the optimized active power

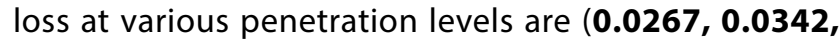

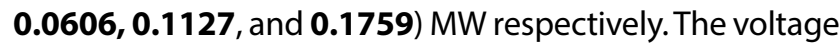
control of four STATCOM devices at a high level penetration is $\mathbf{( 0 . 9 8 9 5}, \mathbf{1 . 0 0}, \mathbf{0 . 9 8 1 0}$, and $\mathbf{0 . 9 8 9 0})$. Figures $\mathbf{1 4}, \mathbf{1 5}$, show the convergence characteristics of power loss minimization at all penetration level. Figure 16 shows the distribution of voltage magnitudes at all buses. As well shown in Figs. 14, 15, the near optimal solution is obtained at a reduced number of iterations, less than 5 trials are required to locate the best solution.

Case 6: Maximization of margin reserve

The MR is an important index to test the efficiency and reliability of practical power system. MR is based 
Table 4 Optimized RD performances under loading conditions: integration four STATCOM devices

\begin{tabular}{llll}
\hline & \multicolumn{2}{l}{ STATCOM Location } & \\
\cline { 2 - 4 } & $10-18-25-30$ & $10-18-25-30$ & 5.4719 \\
\hline PT (MW) & 4.4492 & 5.0591 & 0.8130 \\
QT (MVAR) & 0.5636 & 0.6625 & $\mathbf{0 . 2 7 0 9}$ \\
PLoss (MW) & $\mathbf{0 . 1 7 6 9}$ & $\mathbf{0 . 2 2 9 6}$ & 0.9154 \\
Vmin (p.u) & 0.9313 & 0.9218 & $0.9314,0.9154,0.9689,0.9268$ \\
Vstc (p.u) & $0.9443,0.9313,0.9745,0.9444$ & $0.9366,0.9218,0.9708,0.9368$ & $0.5829,0.1805,0.6283,1.1961$ \\
Size of STATCOM (MVAr) & $0.3953,0.1478,0.4862,1.1700$ & $0.4549,0.1674,0.5284,0.3301$ & $\mathbf{1 . 4}$ \\
Loading factor: Kl & $\mathbf{1 . 1 5}$ & $\mathbf{1 . 3}$ & \\
\hline
\end{tabular}

Bold format in tables indicate the best values achieved

Fig. 10 Convergence characteristics for power loss minimization based four compensators at loading factors: $1 / 1.5 / 1.3$ and 1.4
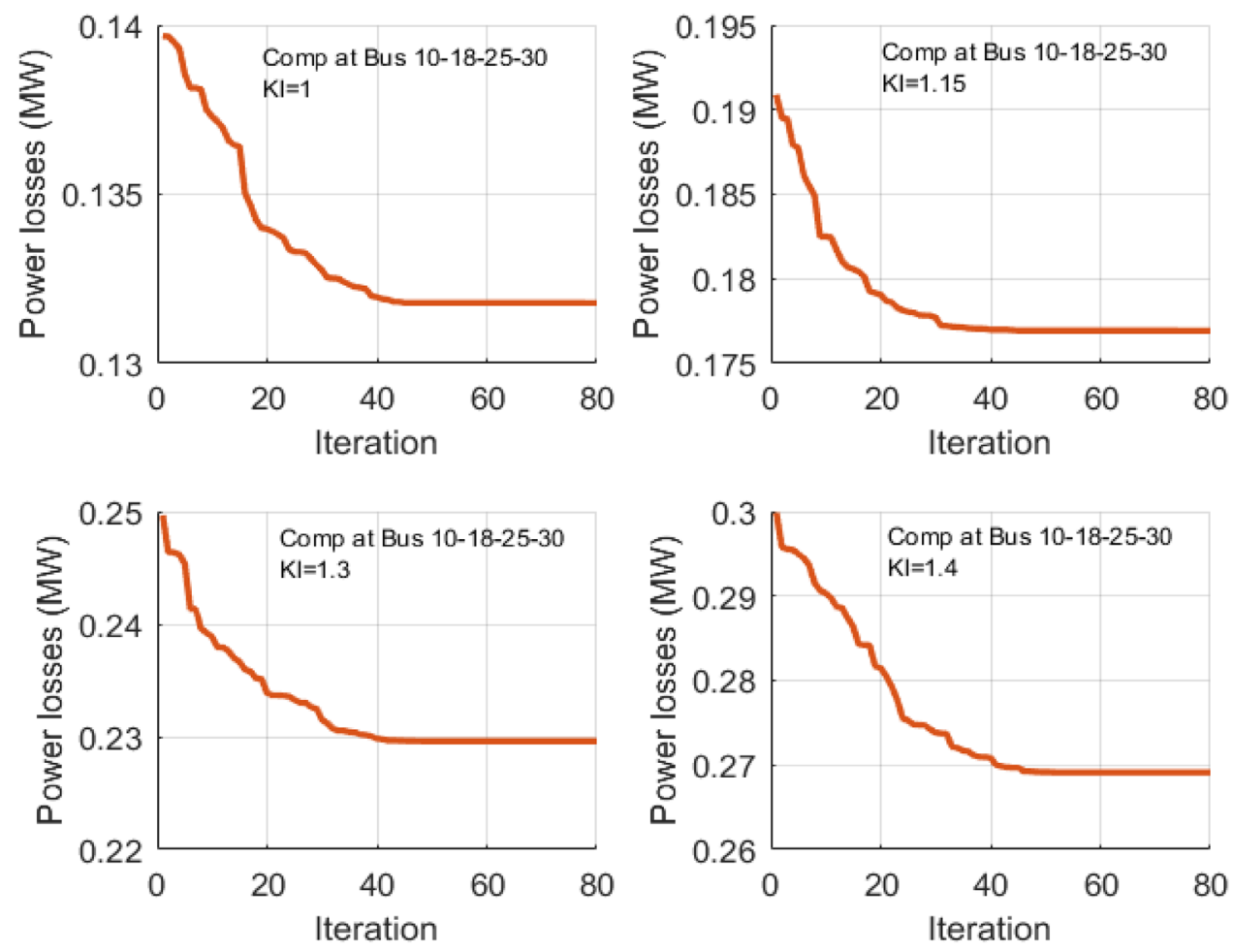

on reducing the amount of reactive current flow at all branches which enhance the capability of transformers to deliver additional active power to new consumers. To show the main impact of this index, the system is optimized with and without PV sources and shunt FACTS devices. The optimized values of MR with and without STATCOM devices and PV sources at normal condition are shown in Table 9. At the base case $(K I=1)$, and without considering the PV sources and shunt FACTS devices, the margin reserve is $24.37 \%$, however by considering both PV sources and the reactive power support of multiSTATCOM devices, the MR is increased to $\mathbf{8 5 . 3 4 \%}$ at penetration level of PV sources equal $53.8358 \%$. This allows the main transformer to deliver additional active power to new consumers without affecting the service quality.

\subsection{Test system 2: RD network of the Sonelgaz company in Algeria}

The departure of $M^{\prime}$ lili (30 kV) is powered from the Mobile station located in Oumeche; it supplies 213 substations HTA / BTA (30/0.4 kV), it consists of 235 lines and 236 buses. Based on 2017 statistical measures delivered by Sonelgaz Company, the maximum power demand to satisfy is $6.0591+j 4.5443$ MVA. The admissible currents in lines are $270 \mathrm{~A}$ for lines with conductor section of 93.3 $\mathrm{mm}^{2}$ and $140 \mathrm{~A}$ for lines with Sect. $34.5 \mathrm{~mm}^{2}$. Figure 17 shows one line schematic representations of departures 
Table 5 Optimized control variables based four STATCOM devices and four PV sources: normal condition: $K I=1$

\begin{tabular}{|c|c|c|c|c|c|}
\hline \multicolumn{6}{|l|}{ STATCOM Location } \\
\hline & $10-18-25-30$ & $10-18-25-30$ & $10-18-25-30$ & $10-18-25-30$ & $10-18-25-30$ \\
\hline PT (MW) & 1.2285 & 1.7322 & 2.2455 & 2.7685 & 3.3060 \\
\hline QT (MVAR) & 0.4753 & 0.4721 & 0.4772 & 0.4814 & 0.6658 \\
\hline$P_{p v 10}$ & 0.5000 & 0.4000 & 0.3000 & 0.2000 & 0.1000 \\
\hline$P_{p v 18}$ & 0.5000 & 0.4000 & 0.3000 & 0.2000 & 0.1000 \\
\hline$P_{p v 25}$ & 0.5000 & 0.4000 & 0.3000 & 0.2000 & 0.1000 \\
\hline$P_{p v 30}$ & 1.0000 & 0.8000 & 0.6000 & 0.4000 & 0.2000 \\
\hline PLoss (MW) & 0.0135 & 0.0172 & 0.0305 & 0.0535 & 0.0870 \\
\hline Vstc (p.u) & $\begin{array}{r}0.9923,1.0000 \\
0.9862,0.9919\end{array}$ & $\begin{array}{r}0.9914,0.9958 \\
0.9913,0.9909\end{array}$ & $\begin{array}{l}0.9818,0.9824 \\
0.9880,0.9814\end{array}$ & $\begin{array}{l}0.9720,0.9688 \\
0.9847,0.9718\end{array}$ & $\begin{array}{l}0.9620,0.9549 \\
0.9813,0.9620\end{array}$ \\
\hline $\begin{array}{l}\text { Size of STATCOM } \\
\text { (Mvar) }\end{array}$ & $\begin{array}{l}0.3181,0.1190 \\
0.4043,0.9937\end{array}$ & $\begin{array}{r}0.3137,0.1294 \\
0.4049,0.9919\end{array}$ & $\begin{array}{l}0.3149,0.1281 \\
0.4069,0.9932\end{array}$ & $\begin{array}{l}0.31930 .12750 .4101 \\
0.9970\end{array}$ & $\begin{array}{l}0.47360 .12750 .4603 \\
0.6332\end{array}$ \\
\hline Loading factor: $K I$ & 1 & 1 & 1 & 1 & 1 \\
\hline Penetration level \% & 67.2947 & 53.8358 & 40.3768 & 26.9179 & 13.4589 \\
\hline
\end{tabular}

Bold format in tables indicate the best values achieved

Fig. 11 Convergence characteristics for power loss minimization based four PV sources (levels: 1-4) and four shunt compensators
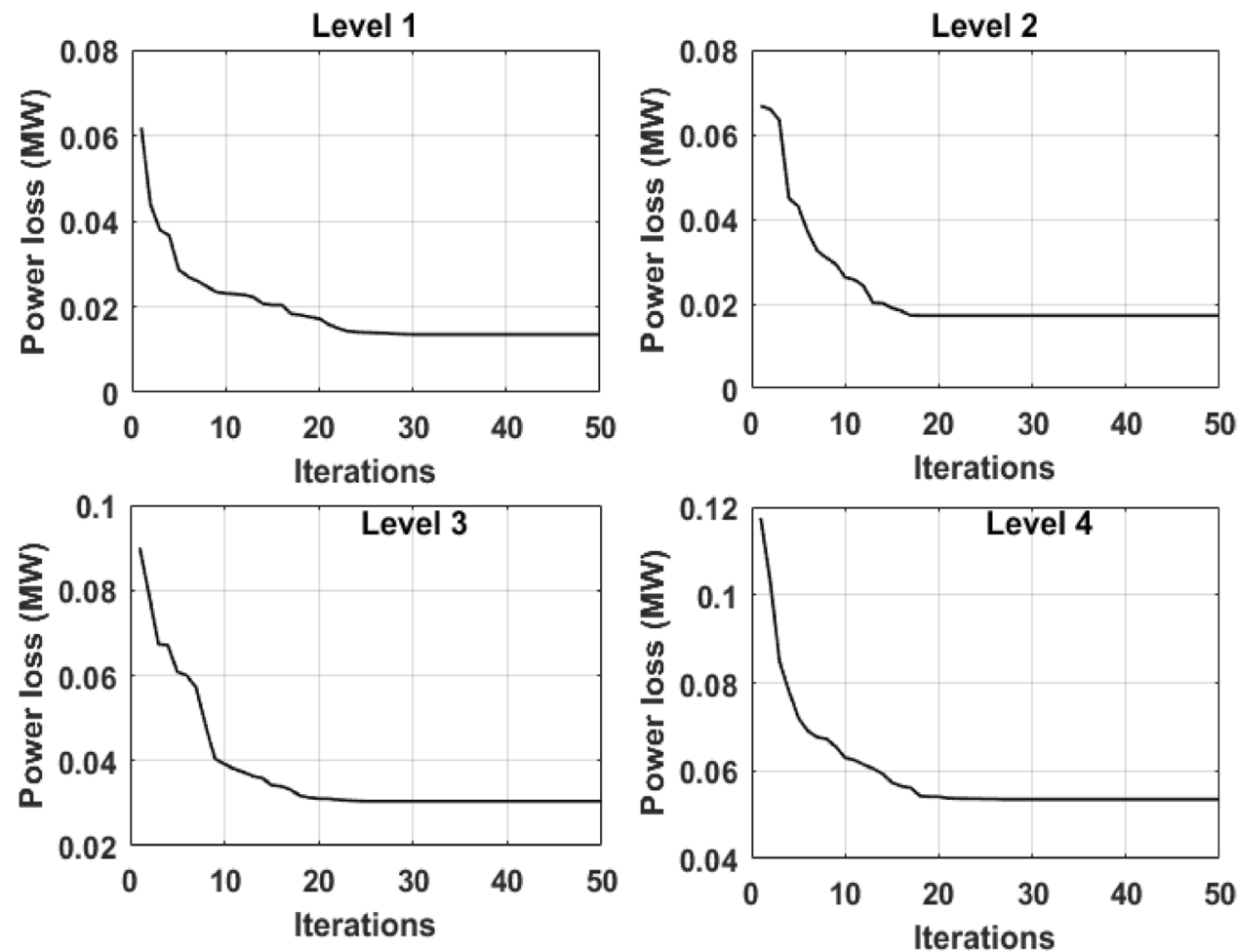

associated with two sub stations located in Tolga and Oumeche (Sonelgaz Company). The one line electric network topology of $M^{\prime}$ 'lili departure is shown in Fig. 18. The departures of M'lili equipped with tie switches to be closed or opened in coordination with other departures at critical situations such as load growth or sever faults described as follows:

- Switch J5193 with departure of Oumeche.
- Switch J5436 with departure 'Ourelal' from mobile station 220/30 kV located in Tolga region.

- Station 542 to Sect. 5436 from departure 'Ourellal' mobile station 220/30 kV located in Tolga region.

It is important to clarify that, based on the technical data delivered by Sonelgaz Company, and due to economic constraints, the number of sectionalizing switches installed in the departure $M^{\prime}$ 'lili are not sufficient and their 


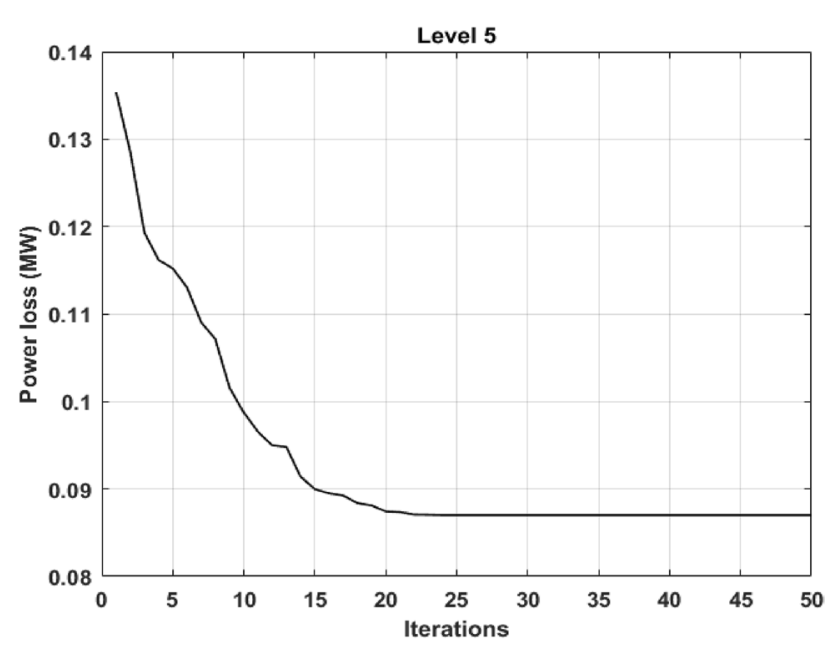

Fig. 12 Convergence characteristics for power loss minimization based four PV sources (level 5) and four shunt compensators at loading factor $K I=1$

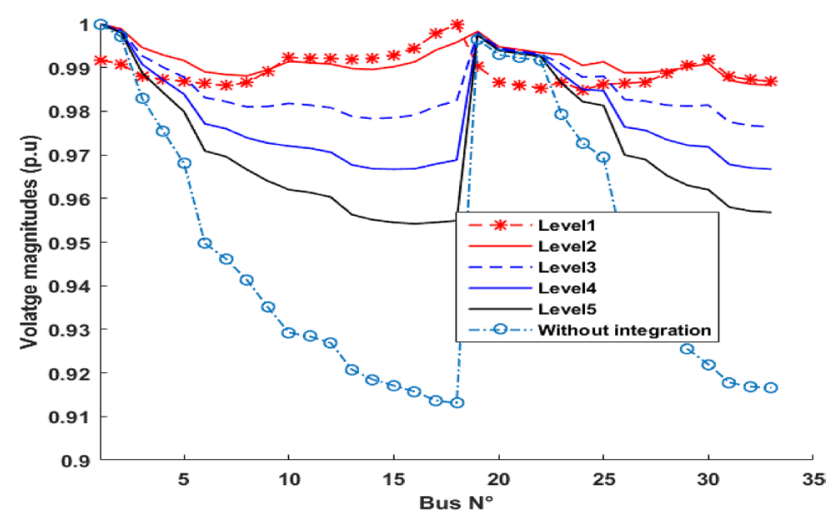

Fig. 13 Voltage profiles with PV sources integration levels and STATCOM devices: $K I=1$

actual location are not optimally chosen. In this study and due to the financial aspect, the proposed optimal reconfiguration strategy is adapted only to the existing operational switches. Also, and due to the incomplete data relative to other departures such as Ourelal departure and Oumeche departure, only the existing operational sectionalizing switches are considered in the proposed reconfiguration strategy analysis.

\subsection{Proposed reconfiguration strategy}

For modern distribution system, several sectionalizing switches $\left(S W_{i}\right)$ and various tie switches $\left(T W_{k}\right)$ must be installed to improve the reliability of modern power system. Each departure is equipped with several sectionalizing switches and a specified number of tie switches to be operated with other departures. The steps of proposed reconfiguration strategy are summarized as follows:

Step 1: run power flow at normal and abnormal condition, to identify the technical state of each departure in terms of the weak and the best connection for each departure.

Step 2: create two initial global matrices, the first one contains, the available sectionalizing switches to be operated in each departure, and the second matrix contains, the available tie switches associated to each departure to be operated.

$$
M_{s w}^{D p}=\left[\begin{array}{cccc}
S w_{1}^{D p 1} & S w_{2}^{D p 1} & \ldots & S w_{n}^{D p 1} \\
\cdot & \cdot & \cdots & \cdot \\
\cdot & \cdot & \cdots & \cdot \\
\cdot & \cdot & \cdots & \cdot \\
S w_{1}^{D p n} & S w_{2}^{D D n} & \ldots & S w_{n}^{D p n}
\end{array}\right]
$$

And at normal condition and initial situation, the matrix of sectionalizing switches of all departures is 'on', and is given as follows:

$$
M_{s w}^{D p}(N)=\left[\begin{array}{cccc}
1 & 1 & \ldots & 1 \\
\ldots & \ldots & \ldots & . \\
\cdots & \ldots & . \\
\cdots & \ldots & \ddots & . \\
1 & 1 & \ldots & 1
\end{array}\right]
$$

Table 6 Comparison results for power loss minimization based PV sources integration: normal condition: $K I=1$

SN Applied Sciences

\begin{tabular}{llllllll}
\hline Methods [20] & Base case & DAPSO & IA & BSOA & PSO & MOPSO & Proposed TSA \\
\hline PV location & $/$ & $10-18-31$ & $6-12-31$ & $13-28-31$ & $14-24-30$ & $3-14-31$ & $10-18-25-30$ \\
PV (MW) & $/$ & 0.681 & 0.900 & 0.6320 & 0.7540 & 1.6762 & 0.5000 \\
& & 0.600 & 0.900 & 0.4870 & 1.0994 & 0.9553 & 0.5000 \\
& & 0.719 & 0.720 & 0.5500 & 1.0714 & 1.3013 & 0.5000 \\
& & & & & & & 1.0000 \\
PLoss (kW) & 202.67 & 92.55 & 81.05 & 89.05 & 71.64 & 87.30 & $\mathbf{7 3 . 7}$ \\
Loading factor: KI & 1 & 1 & 1 & 1 & 1 & 1 & 1 \\
Total size of PV (MW) & $/$ & 2 & 2.52 & 1.6690 & 2.9248 & 3.9328 & $\mathbf{2 . 5}$ \\
Penetration level (\%) & $0 \%$ & $53.84 \%$ & $67.86 \%$ & $44.93 \%$ & $78.73 \%$ & $105.86 \%$ & $\mathbf{6 7 . 2 9 4 7}$ \\
Vmin (p.u) & 0.9131 & 0.9654 & 0.9690 & 0.9554 & 0.9687 & 0.9845 & $\mathbf{0 . 9 6 7 5}$ \\
\hline
\end{tabular}

Bold format in tables indicate the best values achieved 
Table 7 Optimized control variables for power loss minimization based four PV sources: normal condition: $K I=1$

\begin{tabular}{llllll}
\hline PT (MW) & 1.2885 & 1.7934 & 2.3080 & 2.8331 & 3.3693 \\
\hline QT (MVAR) & 2.3504 & 2.3527 & 2.3619 & 2.3783 & 2.4025 \\
$\mathrm{P}_{\text {pv10 }}(\mathrm{MW})$ & 0.5000 & 0.4000 & 0.3000 & 0.2000 & 0.1000 \\
$\mathrm{P}_{\mathrm{pv} 18}(\mathrm{MW})$ & 0.5000 & 0.4000 & 0.3000 & 0.2000 & 0.1000 \\
$\mathrm{P}_{\mathrm{pv} 25}(\mathrm{MW})$ & 0.5000 & 0.4000 & 0.3000 & 0.2000 & 0.1000 \\
$\mathrm{P}_{\text {pv30 }}(\mathrm{MW})$ & 1.0000 & 0.8000 & 0.6000 & 0.4000 & 0.2000 \\
PLoss (kW) & 73.5 & 78.383 & 93.000 & 118.050 & 154.317 \\
Loading factor: KI & $\mathbf{1}$ & $\mathbf{1}$ & $\mathbf{1}$ & $\mathbf{1}$ & $\mathbf{1}$ \\
$\begin{array}{c}\text { Total size of PV } \\
\text { (MW) }\end{array}$ & 2.5 & 2 & 1.5 & 1 & 0.5 \\
$\begin{array}{c}\text { Penetration level } \\
\text { \% }\end{array}$ & 67.2947 & 53.8358 & 40.3768 & 26.9179 & 13.4589 \\
Vmin (p.u) & 0.9675 & 0.9579 & 0.9480 & 0.9378 & 0.9274 \\
\hline
\end{tabular}

Bold format in tables indicate the best values achieved

The matrix of available tie switches is formulated as follows:

$M_{T s}^{D p}=\left[\begin{array}{cccc}T s_{1}^{D p 1} & T s_{2}^{D p 1} & \cdots & T s_{k}^{D p 1} \\ \cdot & \cdot & \cdots & \cdot \\ \cdot & \cdot & \cdots & \cdot \\ T s_{1}^{D p m} & T s_{2}^{D p m} & \cdots & T_{k}^{D p m}\end{array}\right]$

And at normal exploitation, the matrix of tie switches of all departures is given as follows:
$M_{T s}^{D p}(N)=\left[\begin{array}{cccc}0 & 0 & \ldots & 0 \\ \cdot & \cdots & . \\ \cdots & \cdots & . \\ \cdots & \cdots & . \\ 0 & 0 & \ldots & 0\end{array}\right]$

Step 3: for all selected departures, find the best SW (best_SW) to be operated to reduce total power loss without considering TW. Select the best switches.

Step 4: if the selected best_SW chosen are not enough, then, find the best TW (best_TW) associated to the best departure to transfer optimized active power considering the sectionalizing switches.

Step 5: if the best_SW associated and optimized tie switches (best_TW) associated to the first candidate departure are not enough, then the algorithm will search new additional TS (New_best_TW) associated to the second candidate departure.

Step 5: The program will terminate, if the desired objective is located, or the available candidate tie switches associated to all candidate departures are checked.

Stage 1: Power flow analysis at normal condition and considering load growth.

In this first stage, a preliminary analysis of the M'lili departure is achieved. The technical state of the network in terms of voltage profiles, total power losses and current transit in lines are obtained. For this stage, two scenarios are elaborated, in the first scenario, the system is studied at normal condition based on statistical measures elaborated in 2017, the value of total power loss is $0.2307 \mathrm{MW}$, and the low voltage ( $0.9490 \mathrm{p.u}$ ) is located at bus 152 . In the second scenario, the system is studied at loading factor

Table 8 Optimized control variables based four STATCOM devices and four PV sources at high loading condition $(K I=1.4)$

\begin{tabular}{|c|c|c|c|c|c|c|c|c|c|c|}
\hline \multicolumn{11}{|l|}{ STATCOM Location } \\
\hline & \multicolumn{2}{|c|}{$10-18-25-30$} & \multicolumn{2}{|c|}{$10-18-25-30$} & \multicolumn{2}{|c|}{$10-18-25-30$} & \multicolumn{2}{|c|}{$10-18-25-30$} & \multicolumn{2}{|c|}{$10-18-25-30$} \\
\hline PT (MW) & 1.7277 & & 2.4352 & & 3.1616 & & 3.9137 & & 4.6769 & \\
\hline QT (MVAR) & 0.6699 & & 0.6774 & & 0.6734 & & 0.8929 & & 0.6888 & \\
\hline$P_{p v 10}$ & 0.7000 & & 0.5600 & & 0.4200 & & 0.2800 & & 0.1400 & \\
\hline$P_{p v 18}$ & 0.7000 & & 0.5600 & & 0.4200 & & 0.2800 & & 0.1400 & \\
\hline$P_{p v 25}$ & 0.7000 & & 0.5600 & & 0.4200 & & 0.2800 & & 0.1400 & \\
\hline$P_{p v 30}$ & 1.4000 & & 1.1200 & & 0.8400 & & 0.5600 & & 0.2800 & \\
\hline PLoss (MW) & 0.0267 & & 0.0342 & & 0.0606 & & 0.1127 & & 0.1759 & \\
\hline Vmin (p.u) & 0.9791 & & 0.9797 & & 0.9667 & & 0.9445 & & 0.9349 & \\
\hline \multirow[t]{2}{*}{ Vstc (p.u) } & 0.9895 & 1.0000 & 0.9879 & 0.9940 & 0.9743 & 0.9752 & 0.9606 & 0.9560 & 0.9460 & 0.9359 \\
\hline & 0.9810 & 0.9890 & 0.9878 & 0.9867 & 0.9831 & 0.9738 & 0.9786 & 0.9517 & 0.9736 & 0.9460 \\
\hline \multirow[t]{2}{*}{ Size of STATCOM (MVAR) } & 0.4488 & 0.1614 & 0.4516 & 0.1825 & 0.4423 & 0.1800 & 0.6214 & 0.1787 & 0.4677 & 0.1788 \\
\hline & 0.5664 & 1.3942 & 0.5710 & 1.3615 & 0.5715 & 1.3932 & 0.6311 & 0.9704 & 0.5868 & 1.4146 \\
\hline Loading factor: $K I$ & 1.4 & & 1.4 & & 1.4 & & 1.4 & & 1.4 & \\
\hline Penetration level \% & 67.2947 & & 53.8358 & & 40.3768 & & 26.9179 & & 13.4589 & \\
\hline
\end{tabular}

Bold format in tables indicate the best values achieved 
Fig. 14 Convergence characteristics for power loss minimization based four PV sources (levels: 1-4) and four shunt compensators at loading factor $K I=1.4$
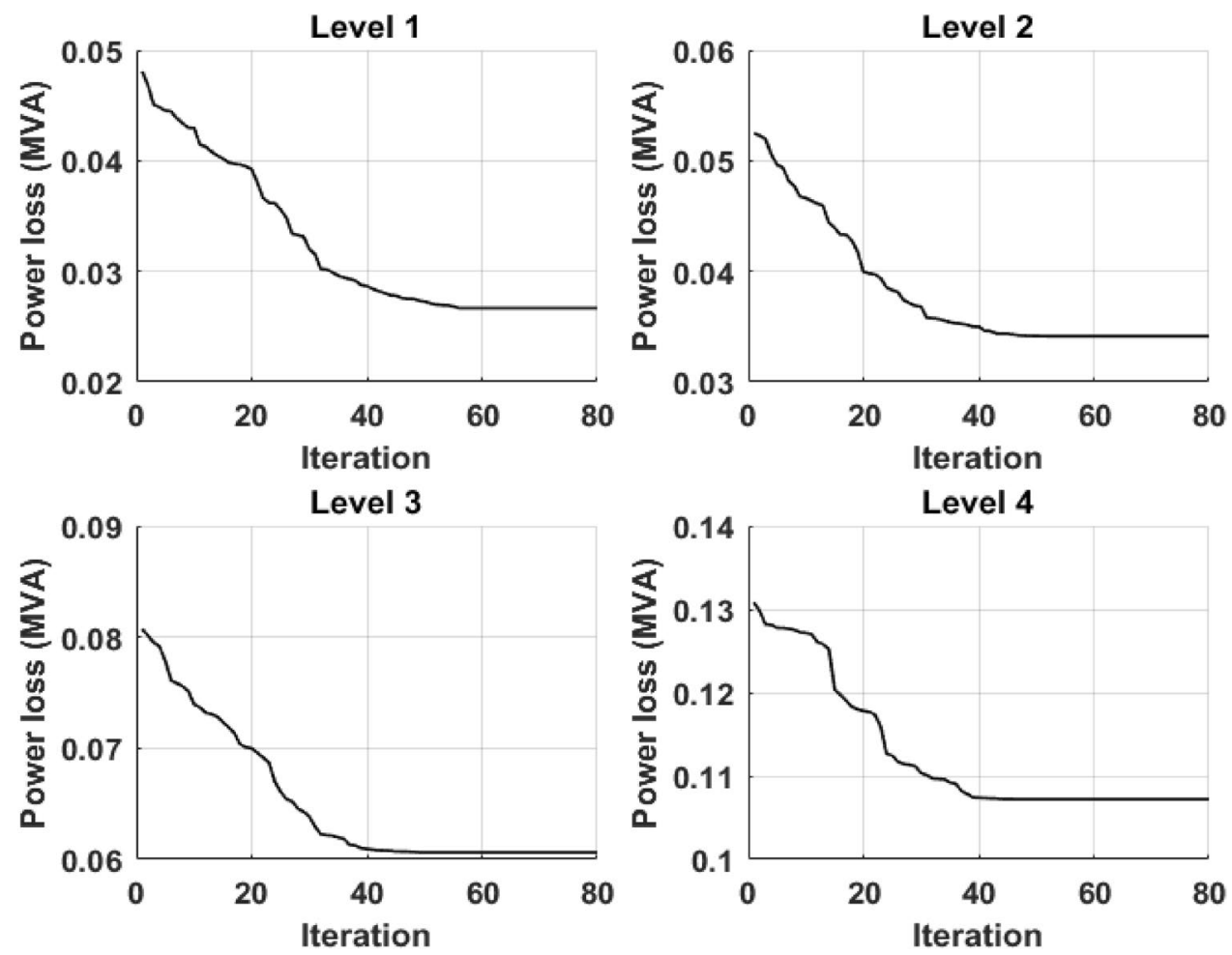

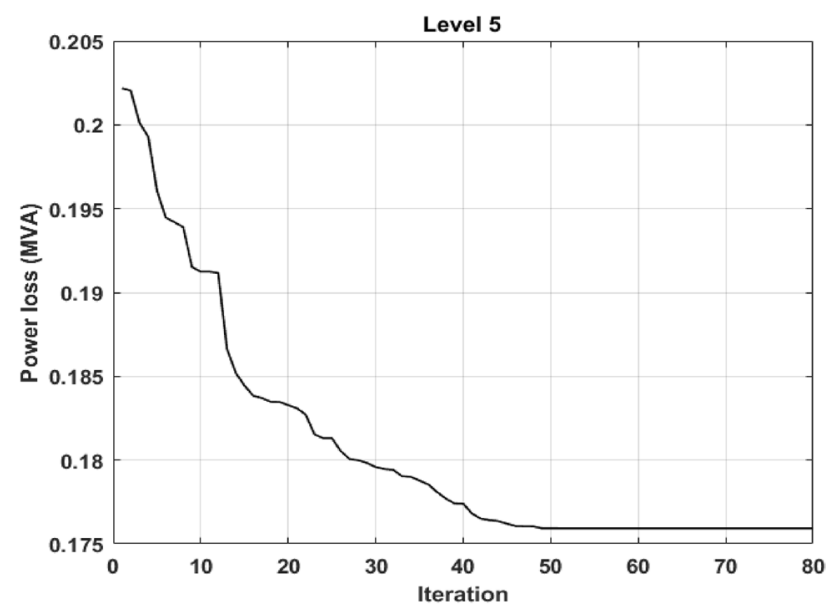

Fig. 15 Convergence characteristics for power loss minimization based four PV sources (level 5) and four shunt compensators at loading factor $K I=1.4$

equal 1.7391. The minimum voltage magnitude $0.9079 \mathrm{p.u}$ is also located at bus 152; the value of total power losses is incremented to $0.7497 \mathrm{MW}$. Figure 19 shows the distribution of voltage magnitudes at the normal case and considering load growth.

Stage 2: Reactive power planning at normal situation without reconfiguration strategy

To improve the performance of $M^{\prime}$ 'ili network at normal condition and considering load growth in terms of reduction of total power loss and improvement voltage

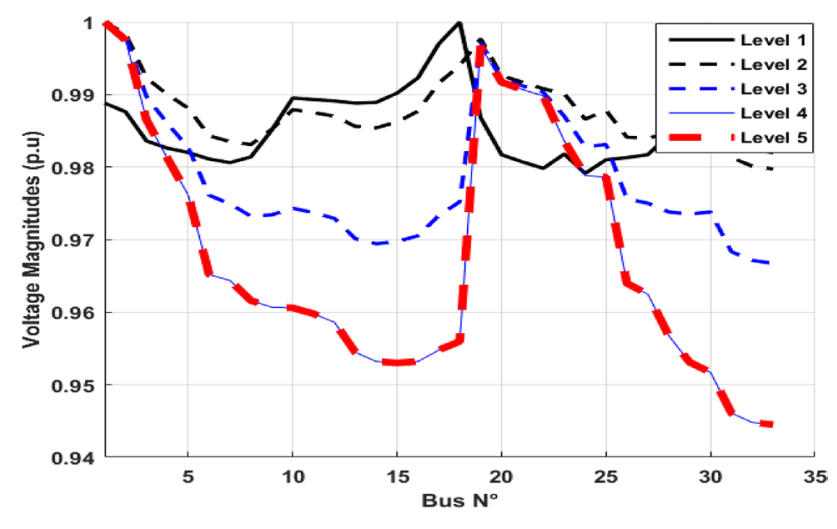

Fig. 16 Voltage profiles with PV sources integration levels and STATCOM devices: $K I=1.4$

profiles, a reactive power planning strategy based STATCOM device is proposed. One and two STATCOM devices are investigated and installed at two candidate buses 152 and 53. By considering the integration of one STATCOM at bus 152 , the optimized value of total power loss achieved is $0.20727 \mathrm{MW}$, the minimum voltage 0.9541 is located at bus 236; the optimized reactive power achieved is 1.1781 MVAR. The convergence characteristic for optimal power losses is shown in Fig. 20.

By installing one compensator at bus 53 , the total power losses achieved is $0.1986 \mathrm{MW}$, the magnitude of minimum voltage is 0.9509 p.u located at bus 152 , and the optimized reactive power delivered by the compensator 
Table 9 Optimized MR with and without STATCOM devices PV sources at normal condition $(K I=1)$

\begin{tabular}{lllllll}
\hline & Without STAT- & \multicolumn{2}{l}{ With STATCOM and PV sources } \\
\cline { 3 - 7 } & COM \& PV & Level 1 & Level 2 & Level 3 & Level 4 & Level 5 \\
\hline Penetration level & $/$ & 67.2947 & 53.8358 & 40.3768 & 26.9179 & 13.4589 \\
Loading factor: $K I$ & $\mathbf{1}$ & $\mathbf{1}$ & $\mathbf{1}$ & $\mathbf{1}$ & $\mathbf{1}$ & $\mathbf{1}$ \\
MR \% & 24.37 & $\mathbf{8 5 . 2 4}$ & $\mathbf{8 5 . 3 4}$ & $\mathbf{8 5 . 1 8}$ & $\mathbf{8 5 . 0 5}$ & $\mathbf{8 4 . 9 4}$ \\
\hline
\end{tabular}

Bold format in tables indicate the best values achieved

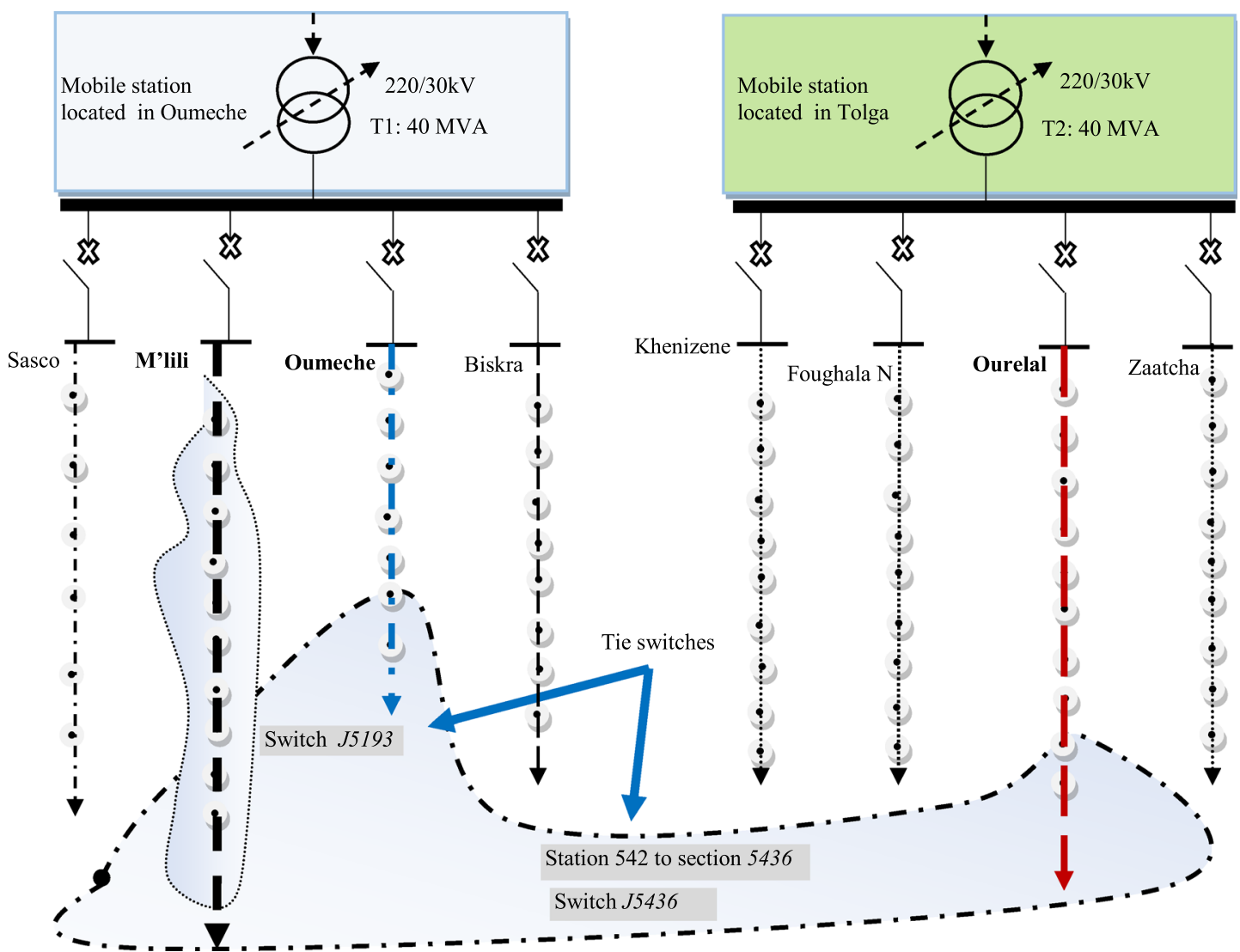

Fig. 17 One line schematic representations of departures associated to two sub stations located in Tolga and Oumeche (Sonelgaz Company)

is 1.1681 MVAR. It is clear that the performances of the RD are improved by considering the installation of STACOM device at bus 53 . The convergence characteristic for total power losses minimization is shown in Fig. 21.

In the last scenario two compensators are considered simultaneously. The total power loss optimized to 0.1762 $\mathrm{MW}$, the optimal value of reactive power of the two compensators installed at buses 53 and 152 are 1.0958 MVAR and 1.0695 MVAR respectively. The minimum voltage magnitude is 0.9624 p.u located at bus 231. It is important to note that the integration and coordination between two compensators improve the performance of the RD compared to case with only one compensator. Figure 22 shows the convergence characteristic of total power loss minimization considering two compensators.
Stage 2: Reactive power planning at load growth without consideration network reconfiguration

In order to achieve reliable decision about the number and the size of STATCOM devices to be installed in practical power systems it is required to optimize the performances of distribution power system under load growth. For this case, the reactive power planning is realised considering load growth. It is found that by installing one compensator at bus 152, the optimized value of total power loss achieved is $0.6583 \mathrm{MW}$, the minimum value of voltage is 0.9160 located at bus 236 , and by installing one compensator at bus 53 , the total power loss achieved is $0.6457 \mathrm{MW}$, the minimum value of voltage magnitude is $0.9111 \mathrm{p} . \mathrm{u}$ located at bus 152 . 


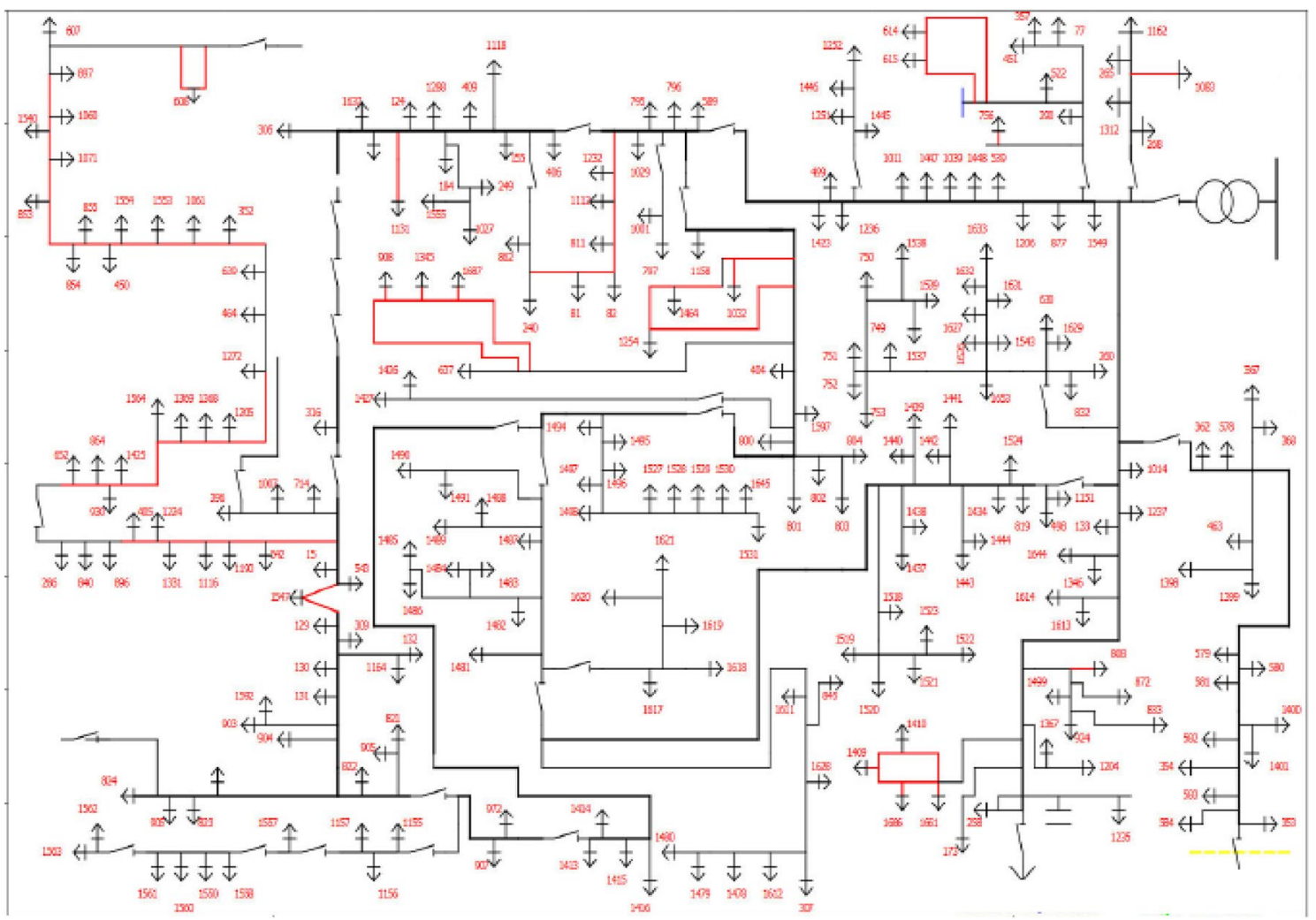

Fig. 18 One line electric network topology of M'lili departure with 236 buses

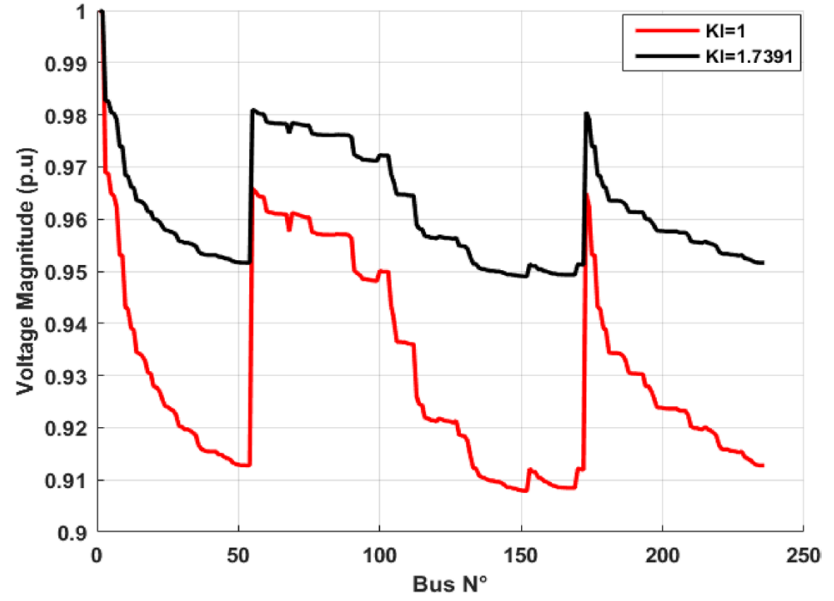

Fig. 19 Distribution of voltage magnitudes at normal condition and considering load growth

Figure 23 shows the convergence characteristics for power loss minimization under load growth $(K I=1.7391)$ based STATCOM devices. Table 10 shows the optimized results for reactive power planning at normal and under load growth.

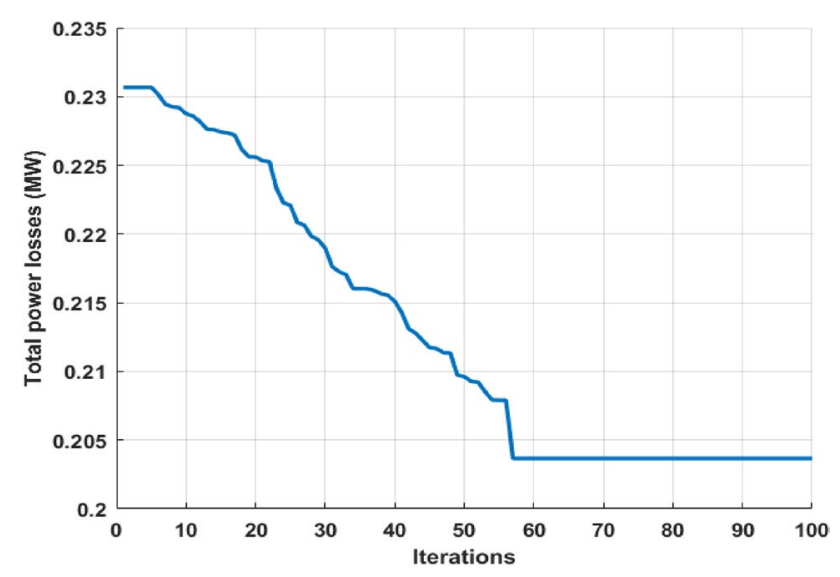

Fig. 20 convergence characteristic for power loss reduction at normal condition based one STATCOM located at bus 152

Stage 3: Reactive power planning at normal and abnormal situations with consideration of reconfiguration operation

The reactive power planning is a vital technical action to be considered by experts to improve the performance of modern power system in terms of improving the voltage profiles and reduction of total power losses. However, reactive power planning considering technical and economical 


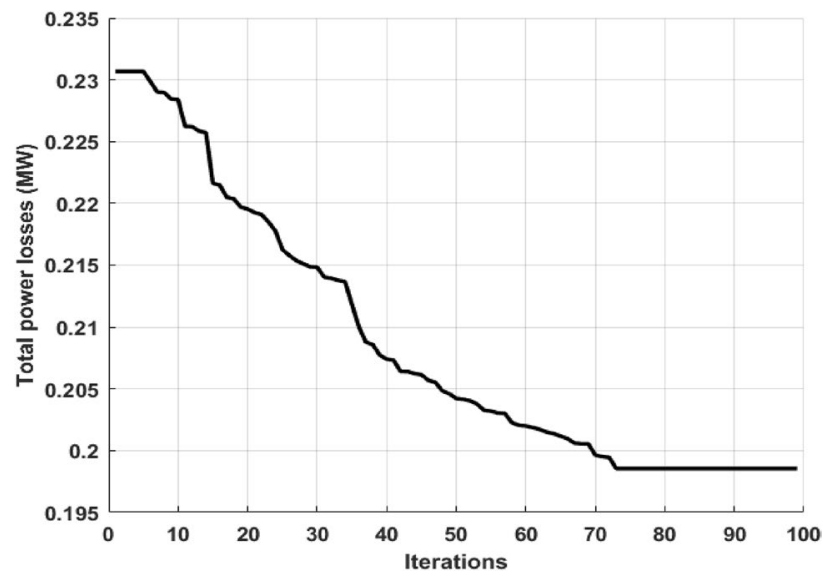

Fig. 21 convergence characteristic for power loss reduction at normal condition based one STATCOM located at bus $\mathbf{5 3}$

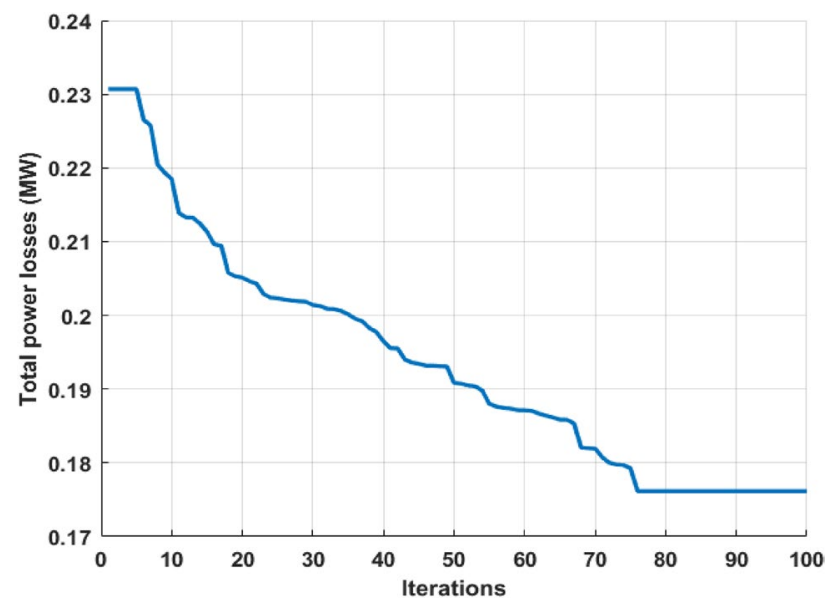

Fig. 22 convergence characteristic for power loss reduction at normal condition based two STATCOM located at buses $\mathbf{5 3}$ and 152

aspect must be done in coordination with reconfiguration operation under critical situations. In this stage, the reactive power of STATCOM devices to be exchanged with the network are optimized considering the best locations of sectionalizing switches and tie switches installed by Sonelgaz Company at specified locations. It is found that sectionalizing switches and total number of tie switches proposed by Sonelgaz Company are not sufficient and their locations are not well chosen. For the economic aspect, only the available three tie switches are considered within the optimization process. At the margin stability, the loading factor is 1.7391; the TSA is applied to find the best tie switches associated to all candidate departures and sectionalizing switches related to M'lili departure to be operated in coordination with reactive power of STATCOM devices. In the first stage, and based on the steps of reconfiguration strategy, the TSA identifies the optimal tie

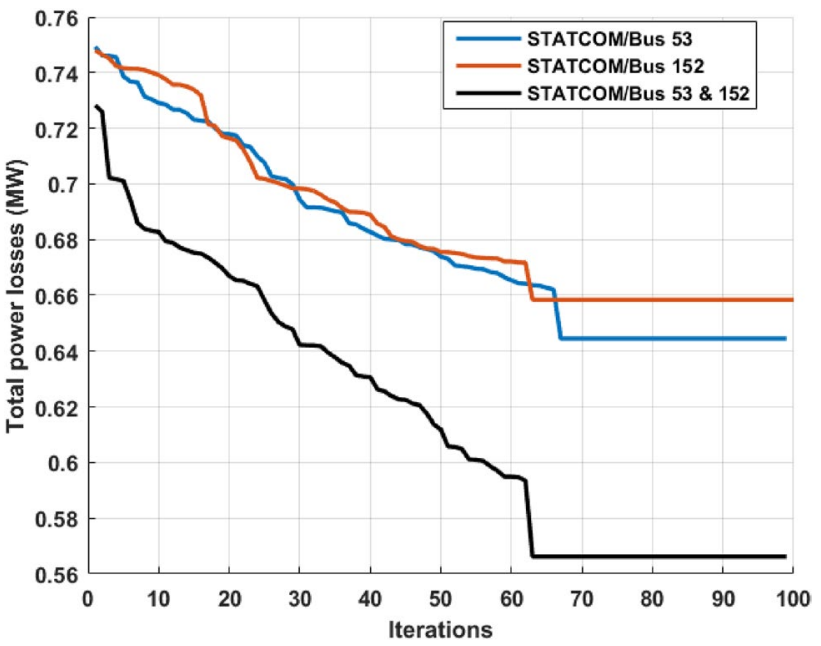

Fig. 23 Convergence characteristic for power loss reduction under load growth $(K I=1.7391)$ without reconfiguration strategy: One STATCOM at Bus 53, 152, and two STATCOM at Buses 53-152

Table 10 Optimized results at normal and under load growth: reactive power planning

\begin{tabular}{lllll}
\hline \multicolumn{4}{l}{ STATCOM Location } \\
\cline { 2 - 5 } & $\begin{array}{l}\text { Without STAT- } \\
\text { COM }\end{array}$ & 53 & 152 & 53 and 152 \\
\hline $\begin{array}{l}\text { Loading factor } \\
(K I)\end{array}$ & 1.7391 & 1.7391 & 1.7391 & 1.7391 \\
PLoss (MW) & 0.7497 & 0.6457 & 0.6583 & 0.5662 \\
$\begin{array}{l}\text { Vmin (p.u) } \\
\text { Critical Bus }\end{array}$ & 0.9079 & 0.9111 & 0.9160 & 0.9319 \\
$\begin{array}{c}\text { Q_STATCOM } \\
\text { (MVAR) }\end{array}$ & 0 & 152 & 236 & 231 \\
\hline
\end{tabular}

switches to be operated, the best tie switches are located based on minimum power loss generated in M'lili departure, and this choice will not affect the energy quality delivered to other departures (Ourelal and Oumeche), the minimum voltage level is considered as an index of power quality. In the second stage, the TSA is applied to optimize the reactive power of STATCOM devices to be exchanged with the network. Table 11 shows the optimized results under load growth considering reconfiguration and reactive power planning. Figure 24 shows the convergence characteristic for the power loss reduction under load growth and considering reconfiguration strategy for one STATCOM device installed at bus 53 , the total power loss achieved is $0.5337 \mathrm{MW}$, and by installing one STATCOM at bus 152, the total power loss achieved is $0.5765 \mathrm{MW}$, Fig. 25 shows the convergence characteristic for the power loss reduction under load growth with STATCOM device installed in bus 152 . However, by installing two STATCOM, 
Table 11 Optimized results under load growth considering reconfiguration and reactive power planning

\begin{tabular}{|c|c|c|c|c|}
\hline & \multicolumn{4}{|l|}{ STATCOM Location } \\
\hline & Without STATCOM & 53 & 152 & 53 and 152 \\
\hline Loading factor $(K I)$ & 1.7391 & 1.7391 & 1.7391 & 1.7391 \\
\hline PLoss (MW) & 0.7497 & 0.5337 & 0.5756 & 0.4884 \\
\hline $\operatorname{Vmin}(p . u)$ & 0.9079 & 0.9285 & 0.9175 & 0.9323 \\
\hline Critical Bus & 152 & 152 & 236 & 231 \\
\hline Q_STATCOM (MVAR) & 0 & 1.9951 & 1.4942 & $1.7968 / 1.4569$ \\
\hline $\mathrm{N}^{\circ}$ of $(\mathrm{SWi}) /$ switched off & / & 5 & 5 & 5 \\
\hline $\begin{array}{l}\text { Proposed Internal tie switch } \\
\text { (Departure of M'lili): TWi }\end{array}$ & / & 3 & 3 & 3 \\
\hline The best Tie Switch & l & $J 5193$ at & departure & \\
\hline
\end{tabular}

Bold format in tables indicate the best values achieved

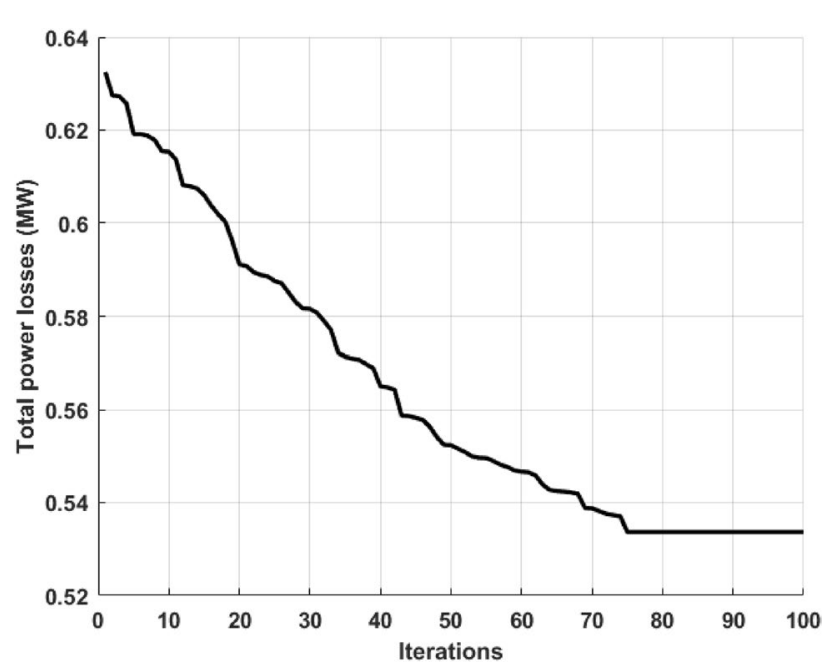

Fig. 24 Convergence characteristic for power loss reduction under load growth $(K I=1.7391)$ considering reconfiguration strategy: One STATCOM located at bus $\mathbf{5 3}$

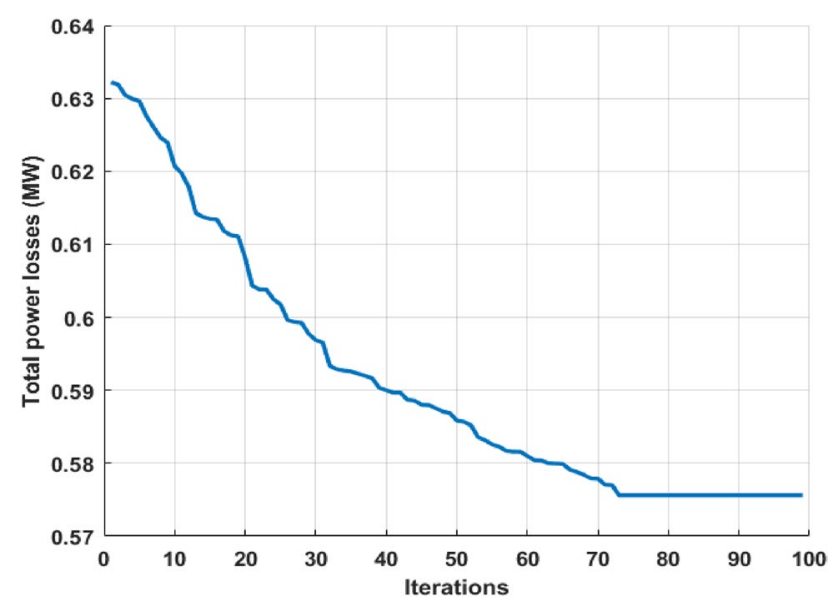

Fig. 25 Convergence characteristic for power loss reduction under load growth considering reconfiguration strategy $(K I=1.7391)$ : One STATCOM located at bus 152

\section{SN Applied Sciences}

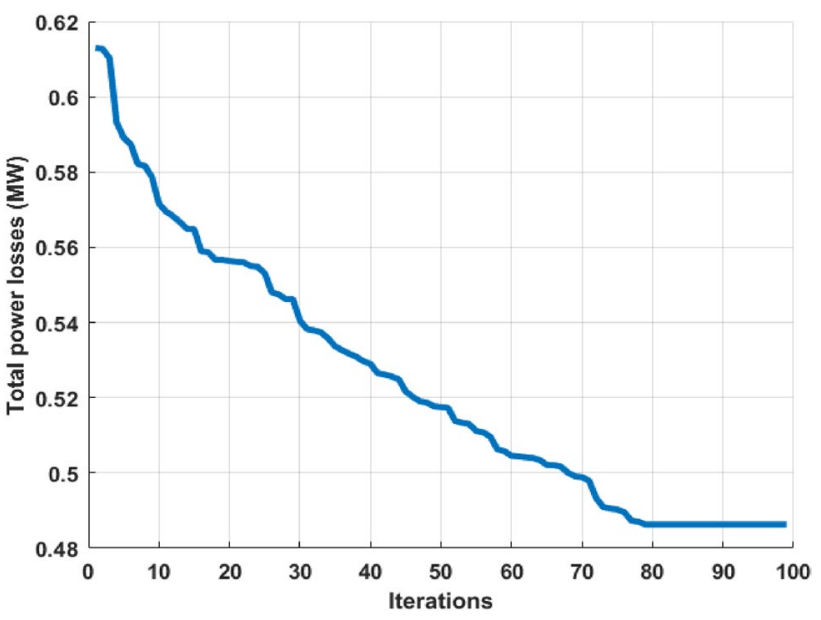

Fig. 26 Convergence characteristic for power loss reduction under load growth $(K I=1.7391)$ considering reconfiguration strategy: Two STATCOM located at buses $\mathbf{5 3}$ and $\mathbf{1 5 2}$

the optimized power loss is improved to $\mathbf{0 . 4 8 4} \mathrm{MW}$. The convergence characteristic for power loss reduction under load growth and with two STATCOM devices installed in bus 53 and Bus 152 is shown in Fig. 26.

\subsection{Overall comments and recommendations}

- To achieve service continuity on all radial distribution systems of Sonelgaz Company (30/0.4 kV) with high power quality in particular at critical situations such as faults and load growth, it is absolutely recommended to install more internal tie switch within each departure. However, this important technical task causes supplementary cost.

- To ensure reliable exploitation of RD electric system in particular in summer period characterized by low voltage and important power loss, it is mandatory to coordinate the reconfiguration strategy with reactive power planning. 
- It is recommended developing interactive energy management software to ensure real-time exploitation of distribution system at low cost investment.

- The optimal location of multi-shunt compensators based FACTS devices and the optimal selection of various sectionalizing and tie switches is a vital task to experts. This operation requires introducing the investment cost of all equipment.

- It is demonstrated that the integration of renewable sources in particular PV sources in coordination with shunt compensator (STATCOM) gives the highest power loss reduction and low voltage deviation at normal condition and at critical loading margin stability.

- For case 4, and by executing the program on a computer with processor i3, the average computation time required to achieve the best solution using the standard TSA is $7.7824 \mathrm{~s}$, however, by using the proposed adaptive TSA, the average computation time required to locate the best solution is $2.36258 \mathrm{~s}$, which is lower and competitive compared to the value obtained using the standard TSA. Our future work will be focused to apply the proposed variant based TSA for real-time application by using parallel processors in solving multi-objective problems related to large-scale reactive power system planning and control.

\section{Conclusion}

This study focuses on the improvement of the technical performance of radial electric distribution system by optimal location and sizing of STATCOM devices and multi-PV sources in coordination with optimizing a certain number of sectionalizing switches and tie switches to be operated. A recent metaheuristic technique called tree seed algorithm is efficiently adapted and applied to minimize the total power losses under normal condition and considering critical load growth. Two practical electric test systems are considered (standard 33 buses and 250 buses of Sonelgaz distribution systems of Algeria) to validate the efficacy and particularity of the proposed planning strategy. It is well demonstrated that the reactive power planning based STATCOM devices in coordination with active power management of multi PV sources will be considered an alternative solution to improve the power quality delivered to customers. However, at important load growth and severe critical faults, the desired power quality delivered to consumers will be affected, which requires the application of a flexible planning strategy based reconfiguration of network topology to achieve high technical and economical objectives. Due to the remarkable results found using the proposed planning strategy based TSA, author will strive to apply an extended version of this algorithm to solve the distribution power system planning considering various dynamic characteristics of loads and taking in consideration the probabilistic and intermittent aspect of photovoltaic and wind sources. Otherwise, by using the parallel concept, the modified TSA may be useful for realtime applications in solving multi-objective power system planning and control for large-scale RD systems.

Acknowledgements I would like to acknowledge the Editor in Chief, and reviewers for their pertinent comments and recommendation, which really improved the quality of my paper. Also, a great thanks to the Sonelgaz Company, distribution centre in Biskra, Algeria, which provided for me the technical data.

\section{Compliance with ethical standards}

Conflict of interest No potential conflict of interest was reported by the author.

Open Access This article is licensed under a Creative Commons Attribution 4.0 International License, which permits use, sharing, adaptation, distribution and reproduction in any medium or format, as long as you give appropriate credit to the original author(s) and the source, provide a link to the Creative Commons licence, and indicate if changes were made. The images or other third party material in this article are included in the article's Creative Commons licence, unless indicated otherwise in a credit line to the material. If material is not included in the article's Creative Commons licence and your intended use is not permitted by statutory regulation or exceeds the permitted use, you will need to obtain permission directly from the copyright holder. To view a copy of this licence, visit http://creativecommons .org/licenses/by/4.0/.

\section{References}

1. Mahdad B (2019) Optimal reconfiguration and reactive power planning based fractal search algorithm: a case study of the Algerian distribution electrical system. Eng Sci Technol Int J 22:78-101

2. Belkacem M, Srairi K (2016) Adaptive differential search algorithm for optimal location of distributed generation in the presence of SVC for power loss reduction in distribution system. Eng Scie Technol Int J 19(3):1266-1282

3. Ehsan A, Yang Q (2018) Optimal integration and planning of renewable distributed generation in the power distribution networks: a review of analytical techniques. Appl Energy 210:44-59

4. Jordehi AR (2016) Allocation of distributed generation units in electric power systems: a review. Renew Sustain Energy Rev 56:893-905

5. Mishra S, Debapriya D, Subrata P (2016) A comprehensive review on power distribution network reconfiguration. Energy Syst 2016:1-58

6. Almoataz Y (2017) Abdelaziz, Ahmed Fathy, A novel approach based on crow search algorithm for optimal selection of conductor size in radial distribution networks. Eng Sci Technol Int J 20:391-402

7. Nojavan S, Jalali M, Zare K (2014) Optimal allocation of capacitors in radial/mesh distribution systems using mixed integer 
nonlinear programming approach. Electric Power Syst Res 107:119-124

8. Naik S, Gopiya DK, Khatod MP, Sharma, (2013) Optimal allocation of combined DG and capacitor for real power loss minimization in distribution networks. Int J Electr Power Energy Syst 53:967-973

9. Muthukumar K, Jayalalitha S (2016) Optimal placement and sizing of distributed generators and shunt capacitors for power loss minimization in radial distribution networks using hybrid heuristic search optimization technique. Int J Electr Power Energy Syst 78:299-319

10. Cassio G, Lindenberg IS, Edmarcio AB, Alfeu JSF, Eduardo CMC (2019) Distribution network reconfiguration using selective firefly algorithm and a load flow analysis criterion for reducing the search space. IEEE Access. https://doi.org/10.1109/ACCES S.2019.2918480

11. Partha PB, Mallipeddi R, Suganthan PN, Gehan AJA (2017) A multiobjective approach for optimal placement and sizing of distributed generators and capacitors in distribution network. Appl Soft Comput 60:268-280

12. Omid S, Arman O, Morteza K, Behnam M-I (2020) Optimal placement of multi-period-based switched capacitor in radial distribution systems. Comput Electr Eng 82:106549

13. Pegadoa R, Ñaupari Z, Molina Y, Castillo C (2019) Radial distribution network reconfiguration for power losses reduction based on improved selective BPSO. Electric Power Syst Res 169:206-213

14. Jafar S, Neda R, Gevork BG (2019) Reconfiguration and DG sizing and placement using improved shuffled frog leaping algorithm. Electr Power Compon Syst 47:16-17

15. Savier JS, Das D (2007) Impact of network reconfiguration on loss allocation of radial distribution systems. IEEE Trans Power Deliv 22(4):2007

16. Kazemi-Robati E, Sepasian MS (2020) Fast heuristic methods for harmonic minimization using distribution system reconfiguration. Electr Power Syst Res 181:106185

17. Prasad K, Ranjan R, Sahoo NC, Chaturvedi A (2005) Optimal reconfiguration of radial distribution systems using a fuzzy mutated genetic algorithm. IEEE Trans Power Deliv 20(2):2005

18. Belkacem M, Srairi K (2013) Solving multi-objective optimal power flow problem considering wind-STATCOM using differential evolution. Front Energy 7(1):75-89

19. Kamel S, Selim A, Ahmed W, Jurado F (2019) Single and multiobjective optimization for photovoltaic distributed generators implementation in probabilistic power flow algorithm. Electr Eng. https://doi.org/10.1007/s00202-019-00878-7

20. Zheng W, Wu W, Zhang B, Sun H, Liu Y (2016) A fully distributed reactive power optimization and control method for active distribution networks. IEEE Trans Smart Grid 7:1021-1033
21. Khan I, Li Z, Yinliang Xu, Wei Gu (2016) Distributed control algorithm for optimal reactive power control in power grids. Int J Electr Power Energy Syst 83:505-513

22. Khan I, Yinliang Xu, Sun H, Bhattacharjee V (2017) Distributed optimal reactive power control of power systems. IEEE Access 6:7100-7111

23. Ahmed A, Diab Z, Rezk H (2018) Optimal sizing and placement of capacitors in radial distribution systems based on grey wolf, dragonfly and moth-flame optimization algorithms. Iran J Sci Technol Trans Electr Eng. https://doi.org/10.1007/s4099 8-018-0071-7

24. Abdelaziz AY, Ali ES, Elazim SMA (2016) Flower pollination algorithm and loss sensitivity factors for optimal sizing and placement of capacitors in radial distribution systems. Electr Power Energy Syst 78:207-214

25. Saddique MW, Haroon SS, Amin S, Bhatti AR, Sajjad NA, Liaqat $R$ (2020) Optimal placement and sizing of shunt capacitors in radial distribution system using polar bear optimization algorithm. Arab J Sci Eng. https://doi.org/10.1007/s13369-020-04747 $-5$

26. Selim A, Kamel S, Jurado F (2020) Capacitors allocation in distribution systems using a hybrid formulation based on analytical and two metaheuristic optimization techniques. Comput Electr Eng 85:106675

27. Roy PK, Sultana S (2020) Optimal reconfiguration of capacitor based radial distribution system using chaotic quasi oppositional chemical reaction optimization. Microsyst Technol. https ://doi.org/10.1007/s00542-020-04885-8

28. Shuaib YM, Kalavathi MS, Rajan CCA (2015) Optimal capacitor placement in radial distribution system using gravitational search algorithm. Electr Power Energy Syst 64(2015):384-397

29. Rizk-Allah RM, Hassanien AE, Oliva D (2020) An enhanced sitting-sizing scheme for shunt capacitors in radial distribution systems using improved atom search optimization. Neural Comput Appl. https://doi.org/10.1007/s00521-020-04799-6,2020

30. Le Van D, Doan DT, Le Cao Q (2017) A highly relevant method for incorporation of shunt connected facts device into multimachine power system to dampen electromechanical oscillations. Energies 10:482. https://doi.org/10.3390/en10040482

31. Servet Kıran M (2015) TSA: tree-seed algorithm for continuous optimization. Expert Syst Appl 42(19):6686-6698

32. Vallem V, Venkata S, Narayana M, Ashwani KS (2018) Optimal coordinate control of OLTC, DG, D-STATCOM, and reconfiguration in distribution system for voltage control and loss minimization. Int Trans Electr Energ Syst 2018:e2752

Publisher's Note Springer Nature remains neutral with regard to jurisdictional claims in published maps and institutional affiliations. 